\title{
"It could turn ugly": Selective Disclosure of Attitudes in Political Discussion Networks
}

\author{
Sarah K. Cowan \\ Assistant Professor, \\ Department of Sociology, New York \\ University \\ sarahkcowan@nyu.edu
}

\author{
Delia Baldassarri \\ Professor, \\ Department of Sociology, New York \\ University \\ delia.b@nyu.edu
}

March 2017

\begin{abstract}
:
This article documents individuals selectively disclosing their political attitudes and discusses the consequences of these communication patterns for social influence and the democratic process. Using a large, diverse sample of U.S. resident adults, we ask under which conditions do people reveal their political preferences versus keeping them close to the vest. We find Americans are more likely to share their opinions with friends and family rather than co-workers and they are more likely to share their opinions on more salient topics. More importantly, they withhold their political attitudes specifically from those with whom they disagree in an attempt to avoid conflict. This produces the experience of highly homogeneous social contexts, in which only liberal or conservative views are voiced, while dissent remains silent, and oftentimes goes unacknowledged. This experience is not the result of homogeneous social contexts but the appearance of them. Paradoxically, the mechanism of selective disclosure, whose goal is to prevent conflict at the micro-level, might lead to the perception of greater division in the larger society.
\end{abstract}


Shelley Capito, a Senator from West Virginia advised U.S. citizens to avoid political disagreements during the holidays: "I mean, politics is dangerous...I think it can really result in some really hurt feelings" (Inskeep, 2011). Senator Capito's counsel may make holidays more enjoyable, but by systematically avoiding political disagreement, U.S. citizens may further isolate themselves in homogeneous political discussion networks in which only liberal or conservative views are voiced, while dissent remains silent, and oftentimes goes unacknowledged. By concealing their attitudes specifically from those with whom they disagree, U.S. citizens will not learn that their friend or co-worker disagrees with them. ${ }^{1}$ Thus, social networks consisting of people with diverse attitudes will instead appear homogeneous to their members. Paradoxically, this mechanism of selective disclosure whose goal is to prevent conflict at the micro-level, fosters the macro-level perception of a greatly polarized public opinion (Baldassarri and Bearman 2007).

In this article we focus on patterns of political disclosure: under which conditions do people reveal their political preferences? While travels, sports, kids, and the weather are topics that easily come up in conversation, politics is a sensitive issue. First, we document how political disclosure varies as a function of the nature of the political issue under discussion, the type of relationship between discussants, and their level of political commitment. There is an established research tradition on political communication networks (Katz and Lazarsfeld 1955, Huckfeldt and Sprague 1995, Zuckerman 2005, Gerber et al 2012). Building on these insights, we carry out a comprehensive analysis of the dimensions that facilitate political discussions, including different types of discussants. Moreover, we go beyond the generic theme of 'political discussion' and document dyadic discussions on a variety of political issues. Second, building on recent research on secret keeping and misperceptions (Cowan 2014), we document the

\footnotetext{
${ }^{1}$ Further, in the face of this silence, they may assume political agreement (Goel et al 2010; Laumann 1969).
} 
presence and prominence of selective disclosure in political discussions, a micro-level mechanism that affects individuals' experience of their social network.

To understand how selective disclosure operates at the micro-level, consider the following example: Susan initiates a discussion on affirmative action, and discloses her support for it, in two separate conversations, one with James, who is equally supportive of the policy, and the other with Walter, who, instead, opposes it (Figure 1.a). Will both James and Walter engage Susan's conversation and reveal their views? Other things being equal, James is more likely to reveal his opinion to Susan than Walter. We call this mechanism selective disclosure: discussion partners are more likely to reveal their preferences in case of agreement. The empirical contribution of this article consists in examining James' and Walter's behavior in detail. Namely, we look at survey respondents' propensities to disclose their political views contingent on them knowing the opinion of their discussion partners.

Note that we adopt a strict definition of selective disclosure, considering only situations in which an actor is aware of alter's view as James and Walter are of Susan's views, and decides whether to disclose his or her own. A similar process may also affect Susan's decision to initiate the conversation; perhaps she only initiates in the face of perceived agreement. External triggers such as a political advertisement on television or a protest, however, may also affect initiation. Given initiation is a separate and distinct behavior we do not examine it here. ${ }^{2}$

An important aspect of selective disclosure is that it introduces a systematic difference between the actual political composition of one's social network and how individuals experience it. If Walter decides to do not reveal his preferences (Figure 1.b), Susan's experience of her

\footnotetext{
${ }^{2}$ By not considering this additional opportunity for selective disclosure we may underestimate our phenomenon of interest. However, since our primary goal is to document the presence of selective disclosure in political discussions, it is preferable to underestimate it than running into the risk of over-estimating it.
} 
social network is different from what the network actually is: namely she receives James' positive feedback, but does not learn about Walter's opposite view on the issue.

[insert Figure 1 about here]

The systematic occurrence of selective disclosure in micro-level interactions may produce the experience of politically homogeneous social networks even when individuals' discussion partners carry different political views. For instance, consider a network of 10 people. For simplicity's sake, 5 are Democrats and 5 are Republicans, and each person talks about politics with two members of the same party and one member of the other party. Let's also assume that the chance of revealing one's political view is $100 \%$ in case of agreement, and $70 \%$ in case of disagreement. Under these circumstances, some people reveal their political view to a disagreeing interlocutor but they do not hear about that disagreement. In our example, the result after all of the conversations is that, on average, 3 out of 10 people experience no disagreement when in fact, disagreement exists but is kept hidden.

Selective disclosure prevents individuals from hearing opposing viewpoints and this is believed to affect the democratic process. Political discussions help form and modify political attitudes (Katz and Lazarsfeld 1955; Huckfeldt and Sprague 1995; Huckfeldt, Johnson, and Sprague 2004; Huckfeldt, Ikeda, and Pappi 2005; Huckfeldt 2007; Mutz 2002a; 2002b; 2006; Sunstein 2009; Baldassarri 2009). In particular, conversations among like-minded individuals breed extreme opinions whereas cross-cutting conversations - conversations between people who disagree with each other - are a bulwark against these extreme opinions (Sunstein 2009; Mutz 2006). That Susan only hears James' confirmatory opinion may strengthen her own. Had she heard Walter's disagreement, she may have taken a more moderate view. When this process occurs repeatedly, broad polarization can occur specifically because selective disclosure reduces 
cross-cutting conversations. Few scholars have documented the rarity of cross-cutting conversations in contemporary US public opinion (Mutz 2002a; Huckfeldt, Johnson and Sprague 2004; Klofstad, Sokhey and McClurg 2013), however, such infrequency has been mainly explained by the fact that individuals live in politically homogeneous networks and as such have little opportunity to experience disagreement. Here, we provide evidence for an additional reason inhibiting cross-cutting conversations: selective disclosure.

Finally, the biased experience introduced by selective disclosure complicates not only our treatment of political discussion networks, but also our understanding of interpersonal influence dynamics. Existing literature on networks and interpersonal influence largely assumes that individuals accurately know the attitudes of their discussion partners (Huckfeldt et al. 2004; Mutz 2006). However, if people systematically withhold their political attitudes then individuals will have a biased exposure to their acquaintances' attitudes, thus affecting dynamics of interpersonal influence. This consideration is in line with Brashears and Gladstone (2016) recent call for attention to "how the human 'relays' in a network actually process and manipulate information that they are passing on" (p. 34) in their study on error correction in social networks.

To elicit and measure the mechanism of selective disclosure we follow Cowan's novel survey method to detect systematic bias in the perceptions of concealable characteristics (Cowan 2014) and develop a new set of questions that capture the selective disclosure of political views. The general strategy we use to capture and measure the extent of selective disclosure can be applied to other fields of inquiry, thus enriching the core discussion networks toolkit.

This article proceeds by reviewing the relevant literature on political discussion networks, social selection and interpersonal influence, and conversation. On the basis of this literature, we have formed a series of hypotheses regarding disclosure patterns and test them with a large and 
diverse sample of American adults. We find that in the face of disagreement, these Americans often do not share their political beliefs. Instead, they selectively disclose their attitudes in an attempt to avoid conflict. We discuss differences in these tendencies across issues and party identification as well as across domains of social life - family, friendship and work networks. We conclude by outlining the implications of these findings for theory on interpersonal communication, political discussion networks, social selection and influence, and public opinion polarization.

\section{Political Networks and Conversations}

Theorists celebrate cross-cutting social ties and political conversations, particularly among citizens who disagree with each other, as central to a healthy democracy (Lipset and Rokkan 1967; Lipset 1996; Mill 1859; Arendt 1968; Dahl 1961; Habermas 1996). Ideally, citizens would be exposed to different viewpoints and logics, would develop an informed and moderate set of opinions and tolerance for those with whom they disagree. In practice, evidence shows both positive effects of discussion for political deliberation (Luskin, Fishkin, and Jowell 2002) and the limits of deliberative discussion (Jackman and Sniderman 2006; Mendelberg 2002; Hibbing and Theiss-Morse 2002).

Citizens' scant political interest, knowledge and engagement is often regarded as an obstacle to political deliberation (Converse 1963; Carpini and Keeter 1993; Verba, Schlozman, and Brady 1995). Indeed, Americans prefer to talk of other matters than politics (Bearman and Parigi 2004; Small 2013, Lee and Bearman 2017). However, even occasional political conversations can provide information (Katz and Lazarsfeld 1955; Huckfeldt 2001; Parker, Parker, and McCann 2008) and serve as heuristics for political decision-making (Gigerenzer and Gaissmaier 2011; Gigerenzer et al 2011; Baldassarri 2012). 
Most empirical research on political discussion networks has documented the effects of interpersonal influence on public opinion (Katz and Lazarsfeld 1955; Lazarsfeld, Berelson and Gaudet 1948; Berelson, Bernard, Lazarsfeld and McPhee 1954; Huckfeldt and Sprague 1995; Huckfeldt, Johnson and Sprague 2004; Mutz 2006) and political participation (Beck et al 2002; Klofstad 2007; Gerber and Green 2000; Nickerson 2008). Scholars have also disputed whether experiencing political disagreement leads to an increase in political tolerance, or instead to greater polarization, and a decline in political participation (Stouffer 1955; Nunn, Crockett and Williams 1978; Mutz 2006).

Regardless of the effects, cross-cutting conversations are rare. Scholars delineate three mechanisms causing political homogeneity in social networks. First, structural homophily, is a major force in the organization of social life. Most of the commonality of political views within ego's social network is due to the fact that ego shares background and contextual factors with alters. For instance, individuals holding low-income jobs are likely to work with other lowincome workers. To the extent that individuals' economic status affects their political views, we might expect coworkers to share similar political orientation (McPherson et al 2001). Within the imposing constraints of structural homophily, a second mechanism contributes to the political homogeneity: choice homophily whereby individuals choose the members of their social networks because they share their political views. Lastly, in interpersonal influence, the causal arrow is reversed. As individuals learn the political opinions of those with whom they interact, their opinions converge over time. ${ }^{3}$

None of this scholarship addresses selective disclosure and the role of agreement in driving political discussions and opinion change. The three mechanisms refer to the actual

\footnotetext{
${ }^{3}$ Relying on innovative experimental design, a recent stream of scholarship has decoupled the effect of interpersonal influence from political homogeneity that derives from structural and choice selection (Lazer et al 2010; Nickerson 2008).
} 
political homogeneity of social networks. In contrast, the mechanism of selective disclosure affects one's experience of the political homogeneity of the social networks. The systemic withdrawal from conversation to avoid disagreement provides a biased experience of the overall social network, and, as we will discuss in the conclusion, it may in turn also affect dynamics of selection and interpersonal influence in ways that have not yet been fully considered.

The little empirical work on selective disclosure of personal characteristics largely involves stigmatized health secrets - pregnancy loss (Cowan 2014; Lee 1969) and HIV status (Shelley et al 1995). While political opinions may not have a high degree of stigma associated with them, avoiding the topic altogether or selectively disclosing and withholding these opinions, can create the same kind of information gap that similar behavior with "weightier" secrets may (Cowan 2014) and can create perceived segregation (DiPrete et al 2011).

Selective disclosure is not the only mechanism that can bias individuals' understanding of political views in their social networks, making them perceive greater agreement than there actually is. Disagreement may be hindered cognitively by other mechanisms: the false consensus effect, when individuals project their own opinions onto others (see Robbins and Krueger 2005 for a review) or when they tend to estimate that they are more similar to their acquaintances than they really are (Goel, Mason and Watts 2010; Laumann 1969). Alternatively, people might rely on stereotypes, making inferences based on their friends' characteristics (Goel et al 2010). Further, individuals have been found to cognitively privilege information that coincides with their given beliefs, and they might be more likely to rely on such information when forming beliefs on others' opinions (Zaller 1992). While these biases are unintentional, the mechanism of selective disclosure that we document is a deliberate attempt at hiding one's political views in order to minimize the experience of disagreement at the micro-level. Following Kitts, we explain 
misperceptions on the bases of biased flows of information between actors, rather than assuming cognitive or emotional causes (Kitts 2003).

\section{Hypotheses}

Under which conditions do people reveal their political preferences? And when, instead, do they keep them close to the vest? There is little empirical evidence on these questions. Recent work in political science shows that with regard to general discussion (Hayes et al 2005) and discussion of broad categories such as politics, family, entertainment etc. (Gerber et al 2012), Americans prefer topics conversation partners agree upon (see also Huckfeldt and Mendez 2008). This preference for agreement may result in a "barrier to asking" for fear of disagreement (Gibson 2014). However, this research does not provide insights into the specific content of political conversations, nor does it elaborate on the role of the social context in which they take place, or investigate the motivations individuals provide for not talking about politics. Moreover, it does not document selective disclosure in its more extreme form, namely the complete avoidance of conversation topics in case of anticipated disagreement (Dailey and Palomares 2004 document avoidance for a variety of reasons).

In our empirical research we achieve two goals: 1) we investigate how political disclosure varies as a function of the nature of the political issue under discussion, the type of relationship between discussants, and their level of political commitment; 2) we document the sizeable effect of selective disclosure in our sample.

\section{Political Disclosure}

In order to disclose one's opinion on an issue or a political party, the topic must arise in conversation. While previous work has considered agreement based on ideological or party 
identification, political conversations are rarely limited to political identity. Rather, these conversations touch on the contemporary candidates and issues, and their prominence in the political debate determines how often they are discussed. Some issues are more salient ${ }^{4}$ than others, such as, healthcare reform, gay rights, and abortion were in the 2012 Presidential election. We anticipate that salience is another route by which context affects who converses with whom about what. This brings us to hypothesis 1 :

H1: Individuals are more likely to disclose their opinion on issues that are more salient in the political debate in a given historical period.

Disclosure depends on conversation; individuals tend to discuss mostly with their family (Zuckerman 2005; Gerber et al. 2012). Given familial relationships are typically 'strong ties', it is harder to hide political preferences from close relatives than from acquaintances. In contrast, politics is often considered an inappropriate topic of conversation in workplaces, where one encounters more diversity than among friends and family (Mutz and Mondak 2006; Huckfeldt et al. 1995; but see also DiPrete et al. 2011), and perhaps more opportunities for disagreement. Taken together, these considerations lead us to hypotheses 2 and 3 :

H2: Individuals are more likely to disclose their opinion to family members than to friends or coworkers with whom they discuss politics.

H3: Individuals are least likely to disclose their opinion to work colleagues.

Finally, individuals differ in their level of political interest and frequency of political discussion which would systematically affect political disclosure. Namely, H4: Individuals who are interested in politics are more likely to disclose their opinion to their discussion partners than individuals who avoid politics altogether.

\footnotetext{
${ }^{4}$ We define an issue as salient on the basis of its prominence in the public discourse as a whole, although traditionally, scholars have measured issue salience at the individual level by asking whether respondents are particularly concerned with specific issues.
} 


\section{Selective Disclosure}

In order to avoid conflict, individuals will selectively disclose their opinions. Selective disclosure is here defined as the mechanism according to which people are more likely to reveal their opinions to individuals they anticipate will agree with them, and more likely to conceal their opinions from people they might disagree with. In general, selective disclosure may occur in two distinct situations. First, a situation in which ego is aware of alter's opinion and strategically decides not to reveal his/her own. Second, a situation in which ego is uncertain about alter's opinion and decides to avoid the topic. In this paper we opt for a strict definition of selective disclosure as a situation in which ego avoids revealing his/her own opinion contingent on knowing that alter would disagree with him/her. We focus on situations of known disagreement because this is the arena in which we can be certain of strategic selective disclosure. We believe that adopting a strict definition is crucial given that our primary goal is to establish the existence of this phenomenon.

H5: Individuals are less likely to disclose their opinion to those with whom they disagree than those with whom they agree.

\section{Data and Methodology}

For over 25 years much social network scholarship has relied on the ego-network approach to measure basic network features (Fischer 1982; Marsden 1987; Huckfeldt and Sprague 1995) whereby name generator questions elicit names of the respondents' acquaintances and then ask a series of questions about those individuals and relationships (for examples see McPherson et al 2001; 2006; Moore 1990; Acock and Hurlbert 1993; Huckfeldt and Sprague 1995 among many others). The literature on core discussion networks has documented their size 
(Marsden 1987; McPherson et al 2006, 2008, 2009; Fischer 2009; Brashears 2011), composition (Moore 1990, McPherson et al 2001, Small 2013), content and topics of discussion (Bearman and Parigi 2004; Brashears 2014) and segregation patterns (DiPrete et al 2011). Although highly useful, this method is not perfect; it is sensitive to question wording and places cognitive burden on the respondent and interviewer (Marin 2004; Fischer 2009; Paik and Sanchagrin 2013). It does, however, constitute a reliable tool to study the patterns of dyadic interaction and selective disclosure that are the focus of this article. We use a variant of the name generator questions adopted by Cowan (2014).

In our study, we designed and conducted a unique survey of American adults, the “American Political Attitude Communication Survey.” In addition to basic questions on respondent's political views (i.e., ideology, partisanship, and attitudes on specific issues), their level of political engagement, and socio-demographic characteristics, we focused on their perceptions of the attitudes of those in their social context. We gathered information on specific people with whom respondents discuss politics, their knowledge of discussant's political views, and whether opinions on specific topics were shared. In addition, we asked open-ended questions to capture the reasons why opinions were shared or not.

Specific Political Discussion Networks Questions

To reduce cognitive burden, potential discussion partners are divided into two primary groups: immediate family and outside of the immediate family, such as friends, coworkers, other family and acquaintances. Respondents are randomly assigned to answer questions about their immediate family or those outside of their immediate family first. For the purposes of illustration, we will describe the survey as if they were asked about the immediate family first. The opening question of the political discussion module is "Do you discuss politics with anyone 
in your immediate family?" ${ }^{, 5}$ If respondents indicate they discuss politics with someone in their immediate family then a name generator asks them to provide the first name or initials of up to five immediate family members with whom they discuss politics.

A series of questions then capture the discussion patterns with those named individuals with regard to six political discussion topics. We ask whether ego knows the discussion partner's views on each of these topics. When respondents indicate they do know their partner's opinion, they are asked to provide it. When respondents do not know their partner's opinion, they are asked to guess it. ${ }^{6}$

Respondents indicate whether they shared their own opinion to the discussion partner. Respondents then answer an open-ended question to explain their choice to disclose or not: “Why did you [not] tell [name] your views on [issue]?” The open-ended questions had a high response rate and respondents provided detailed responses, particularly when explaining why opinions were not revealed. We developed 15 codes based on identifying common themes across a subsample of the responses. ${ }^{7}$

The survey iterates through each discussion topic for a given name and then proceeds to the next name. The survey then proceeds to a module capturing people outside of the immediate family (specifying whether they are friends, coworkers, etc.) through the same set of questions. Finally, the survey asks "Is there anyone with whom you discuss important matters but do not

\footnotetext{
${ }^{5}$ Accordingly, the parallel question regarding those outside their immediate family is: "Do you discuss politics with anyone who is not in your immediate family, such as friends, coworkers, other family and acquaintances?"

${ }^{6}$ As an example: a hypothetical respondent discusses politics with family-members John and Susan. She is then asked if she knows John's party affiliation; if she does then she is asked to reveal it and if she does not, she is asked to guess. She then reveals whether she disclosed her party identification to John and why or why not. The same series of questions are then asked with regard to John and each of the issues. When completed, the questions begin again with Susan and party identification.

${ }^{7}$ Given the large sample, and the thousands of dyad-topics for which respondents explained their disclosure patterns, we chose to analyze the qualitative data for a random half of the respondents. A research assistant coded the open-ended answers with supervision from the authors. Reasons for disclosing or not could get more than one code. When reported below, reasons for sharing a given opinion were considered as a percentage of disclosures and reasons for not sharing a given opinion were considered as a percentage of non-disclosures.
} 
discuss politics?" If respondents answer yes then they are asked the name generator question and asked an open-ended question as to why they do not discuss politics with that person.

This network generator differs from some classic ones, such as that in the General Social Survey (GSS), in two important ways. First, it does not specify a timeframe in which the conversation must have taken place (e.g. the GSS asks about discussions in the prior six months). Given we are interested in disclosure in the face of known disagreement, we cannot bound when the discussions may have taken place for fear we would miss capturing an informative conversation. Second, we elicit nearly the entire political discussion network, not the core discussion network, which permits us to examine how disclosure may differ among different relations and to consider the implications for polarization across an entire political discussion network. That being said, we limited the number of political discussion partners respondents could have indicated to five for each domains - family and outside of the family. The disadvantage to both choices are that respondents will have different rates of recall across ties and that the respondents may suffer from survey fatigue. That we randomized whether respondents saw the family module or the module on people outside the family assures that neither module is affected by fatigue more than the other. Another disadvantage is that while we include both the core and more periphery network, people who have particularly large political discussion networks (i.e. more than five political discussion partners either in their family or outside of it) would need to choose from among those. In all likelihood, they chose the most important partners but we cannot say for sure. Of course, there are political conversation partners we may have missed such as a conversation about politics among strangers in a public forum whom respondents cannot name. 
While other name generators request discussion partners on important matters, our name generator question provides a clear specification of the discussion topic: politics. Moreover, while previous work on political discussion networks examined discussions of politics generally, or political partisanship (Gerber et al 2012; Mutz 2006), our survey covers specific discussion topics. In addition to party identification, we also examined dyadic conversations on five political issues -- abortion, gay marriage, affirmative action, welfare spending and the 2010 healthcare reform (the Affordable Care Act). We chose these issues because they are central to American politics, have differing degrees of importance for the 2012 Presidential election and cover three major issue-domains: moral, civil rights, and economic issues. To ensure comparability, the specific wording of these questions was taken from the American National Election Survey. Survey Administration and Sample

The survey was administered over the internet to a diverse convenience sample of over 2000 American resident adults; with a completion rate of $75 \%$. There are a number of advantages to this approach including that computer administration avoids the interviewer fatigue the name generator questions can elicit (Paik and Sanchagrin 2013). The primary disadvantage is that the data are not gathered through a probability sampling strategy that coupled with a reasonable response rate would result in a representative sample. We are not particularly concerned that our sample is not representative of the United States population for a number of reasons. First, our hypotheses regard the mechanism of selective disclosure and the relationships between variables. Testing these particular hypotheses, which are not based on raw percentages, does not rely on a representative sample (Singleton and Straits 2005). That is, a sample does not need to be representative to retain the underlying relationship between variables of interest. Second, as we 
argue later, any bias that would result from sample selection would likely diminish the presence of selective disclosure, thus providing a conservative estimate of the mechanism of interest. Third, the only nationally representative study on a related topic showed similar rates of disclosure (Gerber 2012). Lastly, recent research has shown that non-representative surveys, after statistical correction such as we do below, provide responses that are en par with industry gold standards such as Pew and the General Social Survey (Goel et al.). And Gelman et al (2015)'s non-representative poll on the Xbox platform performed as good if not better than traditional representative surveys in voter intention.

We instituted multiple measures to improve data quality and test robustness, most importantly applying post-stratification weights as is done with traditional probability samples to test whether our results are not dependent on sample composition - they do not. This and other measures are discussed in more detail below.

Respondents were recruited in the Fall of 2012 using the online marketplace for tasks, Amazon's Mechanical Turk (MTurk) ${ }^{8}$. MTurk is increasingly being used to recruit samples throughout the social sciences (see Buhrmester et al 2011; Paolacci et al 2010; Sprouse 2011; Mason and Suri 2012; Weinberg, Freese and McElhattan 2014 on MTurk's usefulness and data quality; Horton et al 2011; Eriksson and Simpson 2012 for examples of its use among many others; Goel et al 2015 on its performance compared to Pew and the GSS). This method recruits a sample much like convenience samples often used in sociology and political science research (for a few examples see Armstrong et al 2012; Hinton et al 2011; Willer et al 2013; Small 2013; Wanga et al 2014; Rothschild et al 2014) but one that is particularly diverse MTurk (Ipeirotis

\footnotetext{
${ }^{8}$ There was certainly selection in who chooses to do tasks on Mechanical Turk and who chose to do this particular one but we cannot capture the characteristics of those individuals who did not participate.
} 
2010). Below we discuss our sample, how it differs from the nation as a whole and how that may affect our results.

We instituted a handful of techniques to improve recruitment and data quality from the MTurk sample. First, we compensated the respondents in excess of similar surveys and tasks of a similar length. ${ }^{9}$ Second, we embedded randomization of modules within the survey so that if respondents did drop out partway through, or data quality fell while taking the survey, then no one module would be affected more than others. Lastly, we took measures to get feedback from respondents, including soliciting comments on the survey, piloting it with a smaller group of respondents and monitoring online forums of MTurk users during the pilot and the main data collection to be made aware of any complaints that arose.

Regarding the sample characteristics, Table 1 shows the sample to be demographically and socio-economically diverse. The sample should not, however, be considered representative of American adults generally. However, given its size and diversity the sample can certainly speak to the mechanisms and processes relevant for this article's theoretical contributions. The sample skews younger and more educated than the American population generally. It also skews more interested in politics and more likely to discuss politics. This could lead, if hypothesis 4 is correct, to an over-estimation of disclosure and under-estimation of conversation withdrawal,

\footnotetext{
${ }^{9}$ Specifically, we paid 50 cents per respondent which we may have affected recruitment rates but not data quality (Buhrmester, Kwang and Gosling 2011). Since 2012 when the data were collected, Mechanical Turk has become more popular for survey collection and the price for each task has increased. The mean duration of the survey was 17 minutes and 15 seconds when dropping those above the $95^{\text {th }}$ percentile for length and below the $5^{\text {th }}$ percentile. Those who took an extremely long time for the survey may have begun it, paused and then returned. Unfortunately we do not have data for the duration that each question took and so cannot determine whether that occurred. The $95^{\text {th }}$ percentile took over 49 minutes to complete the survey and pausing seems the likely explanation; the $5^{\text {th }}$ percentile took three minutes. To ensure that our results were not sensitive to how long respondents took to complete the survey, we redid the analyses for two subsamples. The first excluded those below the $5^{\text {th }}$ percentile and above the $95^{\text {th }}$ percentile for survey duration. These results were nearly identical to those shown here. The second subsample looked only at those in the interquartile range for duration. The univariate and bivariate results were nearly identical to those presented here for the full sample. The multivariate results were also nearly identical but there were a few instances in which the coefficients were nearly identical in the subsample and the full sample but they had lost significance in the subsample, likely due to decreased sample size.
} 
however we have no reason to believe that the underlying mechanisms that affect disclosure in our sample are in any way different from those of the general population. Further, research specifically on the effects of survey non-response has shown that political engagement is not correlated with other behaviors or attitudes (Keeter et al 2006).

To test robustness, we calculated survey weights to improve the match between the study population and the American adult population generally as is standard procedure for surveys usually considered probability samples. We then re-did the analyses presented below using these weights. Though the weights effectively changed the sample population in marked ways, there were few substantive differences in the results, indicating the hypotheses we are testing - both in regards to the relationships between variables and the mechanism of selective disclosure -- are not sensitive to differences in the sample composition. To be clear, we are not arguing that the sample is representative of the U.S. resident adults generally, rather that the sample is appropriate to test our hypotheses: consequently, we do not interpret these results as population estimates of disclosure but as a proof its existence. Accordingly, we present the unweighted results; the weighted results and a description of the weighting process are found in the Appendix.

\section{[insert table 1 about here]}

\section{Results}

Eighty-five percent of our respondents report at least one political discussion partner; seventy percent have a discussion partner in their family, and just over half in the non-family network. Among those who have discussion partners, they have, on average, 3.6 discussion partners and fewer discussion partners who are in their immediate family than outside of it. Half percent of the non-family members are friends, a fifth are coworkers, $7 \%$ are extended kin, $4 \%$ 
come from associations and voluntary groups, and 5\% are listed as others. In the rest of the analysis we will consider the latter three groups simply as 'others'.

\section{[insert Figure 2 about here]}

Figure 2 reports the frequency with which respondents disclose their political opinions. ${ }^{10}$ Party identification is shared most often, namely to three-quarters of people with whom they discuss politics. The disclosure rate for specific issues is lower, ranging from 33 to 64 percent. The issues most often disclosed are gay marriage, abortion, and health care reform, while affirmative action and welfare are the least popular. This suggests that respondents are more likely to disclose opinions on more politically salient topics. The rates of disclosure, however, are lower than one might expect, given that the survey asked respondents to name alters with whom they discuss politics and the survey was conducted during the concluding months of the 2012 Presidential election.

In general, respondents were more likely to disclose their opinions to their immediate family and, in many instances, to friends, than to coworkers or other discussion partners, as shown in Figure 3. Abortion is the exception to this pattern which is revealed to friends less often than to family but the gap with coworkers and others remains wide.

[insert Figure 3 about here]

Finally, people who are interested in politics are more likely to disclose their opinions than people who are not. Those who are very interested in politics disclose their opinion to 59 percent of their discussion partners, while those who are not much interested in politics disclose

\footnotetext{
${ }^{10}$ These frequencies report the number of dyad-topics for which respondents reported sharing their own opinion as a proportion of the total number of issue-dyads for which we have data.
} 
only to 44 percent of them. Similarly, those who discuss politics more often are more likely to disclose their opinions.

Overall, these results indicate hypotheses 1, 2, 3 and 4 may be true: people are more likely to reveal their views on salient issues, they feel most comfortable doing it with members of their family and, partly, with friends, while they are least likely to reveal their opinions to coworkers or other people. Interest in politics and frequency of political discussion are also related to greater rates of disclosure.

Next, we ask whether political opinions are revealed strategically, in order to avoid conflict. Namely, we are interested in documenting the mechanism of selective disclosure: ego's deliberate decision not to reveal his/her own opinion to avoid conflict. Operationally, we adopt a strict definition of selective disclosure, as a situation in which ego avoids revealing his/her own opinion contingent on knowing that alter would disagree with him/her. In Figure 4, we examine rates of disclosure distinguishing between situations in which ego knows alter's opinion and they agree, ego knows alter's opinion and they disagree, and ego does not know alter's opinion.

When comparing the first two columns on Figure 4, we find that rates of disclosure are much higher when ego agrees with alter, than when they disagree. For party preferences, disclosure is 92 percent in case of agreement, and 80 percent in case of disagreement. Selective disclosure is even more apparent when discussing political issues: for all five issues disclosure rates in cases of agreement are around 20 percentage points higher than in cases of disagreement.

Second, when respondents did not know their discussion partner's opinions on a given issue, they were unlikely to disclose their own. Rates of disclosure when ego is not aware of alter's political views are much lower than disclosure when disagreement is ascertained, thus we 
believe that selective disclosure when ego does not know his/her discussion partner's opinion is a marginal phenomenon. ${ }^{11}$ Rather, what usually happens in this scenario is that the topic simply did not come up in conversation, hence respondents do not know the alter's opinion, nor do they express their own.

\section{[insert Figure 4 about here]}

To provide further support for our hypotheses we test them in a multivariate framework. Table 2 reports results from logistic regressions predicting the likelihood that ego would disclose his/her partisanship (models 1-2 and 5-6) or political view on specific issues (models 3-4 and 78). Our unit of analysis is the discussion pair for each topic of conversation (dyad-topic), and we control for dependencies by clustering standard errors at the respondent level. ${ }^{12}$ All models include our variables of interest, and several controls, namely respondent's ideology (7 point scale, ranging from 'extremely liberal' to 'extremely conservative') and standard demographic variables. The first four models concern variations in rates of disclosure (hypotheses 1-4), while models 5-8 concerning selective disclosure (hypothesis 5). Accordingly, the former set of models consider the entire sample of dyad-topics, while the latter considers only the dyad-topics in which ego knows alter's opinion on the specific topic.

Models 1 and 2 consider partisanship disclosure, while models 3 and 4 refer to issue disclosure. Models 2 and 4 control for whether the respondent knows his/her discussion partner's view on the topic. As expected from Figure 4, knowledge of alter's view has considerable predictive power on likelihood of disclosure. Important to our argument, the inclusion of this control does not significantly affect our estimates for the variables of interest.

\footnotetext{
${ }^{11}$ This is further corroborated by an additional analysis on respondents' guesses whether alters would agree with them. We find little or no difference in disclosure rates of egos who guessed alter would agree with them and disclosure rates of egos who anticipated disagreement.

${ }^{12}$ Clustering standard errors at the dyad level leads to results similar to those reported here.
} 
[insert Table 2 about here]

First, opinions on the more salient topics are disclosed more often. Opinions on abortion, gay marriage and the healthcare reform were all disclosed more often than opinions on welfare while opinions on affirmative action were disclosed less often. This supports hypothesis 1 .

Second, our respondents were most likely to disclose their political views to family members, over friends, co-workers and those with whom they had another relationship. Not controlling for knowledge (models 1 and 3), respondents were about 3/4 times as likely to disclose their views to friends than family, and they were half as likely, or less, to disclose to coworkers and others. This confirms the bivariate analyses presented earlier and supports hypotheses 2 and 3. Once we control for knowledge of alter's opinion (models 2 and 4), the distinction between friends and family disappears, while the difference between these two discussant types and coworkers and others remains pronounced.

Third, more politically-interested respondents disclose more often. This is true when interest in politics is measured by a self-report of their interest (as shown here) or by a report of the number of days they discussed politics in the past week (results available upon request). This supports hypothesis 4 .

In sum, issue salience, the type of relationship, and interest in politics, along with knowledge of alter's opinion all predict whether individuals disclose their political views. Almost no socio-demographic characteristic significantly correlates with disclosure patterns, while political ideology does relate to rates of disclosure: those who have the most extreme ideological positions are consistently more likely to disclose their political views. 
To test our hypothesis regarding selective disclosure, we restrict our sample to dyadtopics in which respondents know alters's view on the specific discussion topic for the reasons outlined above. ${ }^{13}$ Models 5 and 6 of Table 2 concern the disclosure of partisanship and models 7 and 8 consider opinions on specific issues. In models 6 and 8 we control for agreement.

When egos share an allegiance to a political party with alters, they are 2.74 times more likely ${ }^{14}$ to disclose their affiliation (model 6). This indicates respondents are selectively disclosing their opinions. The introduction of agreement only marginally changes the relationship between disclosure and the other variables in our model. Conversations with family and friends remain more conducive to disclosure than conversations with coworkers or others. Lastly, interest in politics is positively related to disclosure of party identification.

Agreement is even more predictive of disclosure when considering conversations on specific issues (models 7 and 8). Respondents who know they agree with alter's opinion on a given issue are 3.5 times more likely ${ }^{15}$ to share their own opinion than when they know they disagree. These results fully support hypothesis 5 : respondents share their opinions with those who agree with them and keep them secret from those who disagree with them. As with partisanship, the introduction of agreement into our model does not alter the disclosure rates within different networks, levels of political interest, and type of issue. ${ }^{16}$

We now turn to open-questions responses to review the reasons respondents provided for discussing, or not, their political views. These analyses are presented for all of the sample, whether the respondent knows of the alter's opinion or not. Because there were limited

\footnotetext{
13 Many topics never arise in conversation. As such, the respondents in our sample cannot know their discussion partner's opinion and those are excluded from this analysis.

${ }^{14}$ The average marginal effect of agreement on the disclosure of partisanship is $10 \%$.

${ }^{15}$ The average marginal effect of agreement on the disclosure of opinion on specific issues is $17 \%$.

${ }^{16}$ With the only exception of opinion on gay marriage, whose rate of disclosure is not different from that of welfare issues once we control for agreement.
} 
differences across the issues and party identification, the results are reported together. When political topics arise in discussion, that alone is enough to prompt disclosure. Others disclose specifically when discussion partners agree with them. When our respondents do not disclose an opinion it is usually not as a strategy in the face of disagreement but because the topic does not come up in conversation at all. A substantial minority of the instances of non-disclosure are due to selective non-disclosure, when people refrain from disclosing their opinions in the face of disagreement. This is further evidence in support of hypothesis 5 .

The most common reason for disclosure was the topic merely came up in conversation (19\% of disclosures). ${ }^{17}$ Respondents also shared their opinion because they specifically knew the other person agreed with them ( $17 \%$ of disclosures). As one respondent explained, "it is easier to talk to someone about a subject that you basically agree on." Respondents explain thirteen percent of their disclosures in terms of either their own personal characteristics or circumstances or those of their friends. One explains discussing abortion with a friend, "her girlfriend got raped and had an abortion so we talked about it and told each other how we felt." Another describing a conversation about welfare, "I am disabled and rely on Social Security, Medicare, and food stamps... so it gets discussed often."

Though not as common, respondents also shared their opinions because of an external trigger (6 percent of disclosures) or for matters of intimacy (12 percent of disclosures). For example, respondents often cite seeing protestors. Media triggers came from a variety of venues; one respondent referenced a television sitcom, "She won't let her kids watch Glee because of the gay couples on the show, and the issue came up about gay marriage and we discussed it" and

\footnotetext{
${ }^{17}$ Respondents here merely provided a generic response of "it came up in conversation."
} 
another cited a news report on welfare. Though the reasons did not differ by issue greatly, personal reasons was more common for discussing gay marriage than for any other issue.

Disclosure was also considered in relation to intimacy. Respondents describe sharing their opinions with others because "we are close" or because "she is my mother. We trust each other to talk about anything." Similarly, respondents keep their opinions quiet when intimacy is not present; as one explains regarding opinions on abortion, "We are coworkers. We do not touch on topics so important." Others use political opinions to determine whether to continue a relationship. As one respondent explains "I told her while we were dating. I feel that I couldn't be with someone that opposes my political views."

Mostly people did not share an opinion because the topic did not come up in conversation. This was the case for over half of the non-disclosures. Here respondents felt the opportunity to share did not occur and therefore this does not qualify as self-censorship (as defined by Hayes et al 2005). Given that respondents had already articulated they knew the alter's political opinion, the knowledge may have been obtained through means other than conversation. Respondents often actively refrained from sharing their opinion. Twenty-three percent of the time when respondents did not share, it was because they did not want to discuss politics with their conversation partner. Respondents point to the challenges of discussing with certain people, "I avoid talking politics with her because she is an ignorant jerk." Others simply state that they do not want to discuss a point because they disagree on that topic.

Respondents additionally refrain from discussing politics if they think it will cause an argument. One respondent kept quiet on healthcare reform explaining, "My father is against the reform, and he usually gets pretty angry about it. I didn't want to start anything, so I keep my mouth shut about it." Another explains with regard to welfare, "I've asked her about her views 
and she gave me a very lengthy angry response so I choose not to mention mine because they are the complete opposite. She's very stuck in her ways and it's not a battle I want to fight." Another kept her opinion on gay marriage secret from her mother "Because I do not want to get in a fight with her. We both are strongly opinionated people and it could turn ugly if I tell her my views on gay marriage."

These explanations provide insight into the negative relationship between disclosure and disagreement as seen in the multivariate analyses above. People find it easier and more comfortable to discuss their opinions with those who agree with them, avoiding those who disagree with them or whom may be angered or upset by the disagreement. These patterns of selective disclosure favor the voicing of assenting beliefs over dissenting beliefs and create a bias between the discussed opinions and the privately held ones. This is not because people lie; they simply withdraw from conversation.

The analyses thus far regard dyads in which the respondents have indicated they discuss politics. People do not discuss politics with everyone in their life. For some they do not have a close enough relationship; for others, they discuss important matters but not politics. Over half of the sample indicated there are people with whom they discuss other important matters but not politics. These people span every relationship -- about even numbers of immediate family and friends (37 percent and 40 percent respectively) and the rest were other relationships.

Primarily they avoid discussing politics to avoid disagreement. As one described, "I like to avoid these sorts of conflicts with my family... I really don't enjoy talking about politics much, especially if it's going to end in conflict." Another explains, "I think she would disagree with me in most areas of political thought so I don't initiate those types of conversations." 
People also do not discuss politics because it is uninteresting to them. As one man explained, "I like talking to him about his life and mine...I can trust him when I need to talk to someone about something serious. Politics just don't play into that." Another woman described it this way: "We are friends from Bible class. I don't go around just talking politics to everyone because I feel there is more to life than that. So we like to talk about the guys we're dating, hanging out, traveling, hobbies...”

In summary, this diverse sample of U.S. resident adults are sensitive to the fervent disagreements that political discussions can evoke and therefore avoid disclosing their opinions to those with whom they know they will disagree or with whom they think there will be a conflict. In some instances, this entails not speaking of specific issues with certain individuals and for many this entails not discussing politics at all with particular discussion partners.

\section{Discussion}

We have documented that individuals in the United States prefer to reveal their political opinions to those who agree with them and often keep them secret from those who disagree with them. That is, when individuals know their discussion partner's opinion, they are more likely to disclose their own political views when the two are in agreement, and to withhold them when facing disagreement; the latter resulting in the partner losing the opportunity to experience disagreement. This phenomenon is substantial and present when discussing politics generally and specific issues. Sample limitations prevent us from generalizing our estimates to the U.S. adult

population, although, the only nationally representative study on the topic reported comparable rates of political disclosure (Gerber et al. 2012). We can instead comfortably conclude about the presence and sizeable effect of selective disclosure in our sample, a mechanism that results in systematically distorted perceptions of the opinions in one's social network. To support this 
finding, we employed a variety of robustness tests, most importantly, post-stratification weights which showed the results are not sensitive to population composition.

Second, our results show that specific issues are discussed less often than political party membership. This complements extant scholarship, in which researchers often rely on a single political discussion item related to partisanship, thus likely overestimating the frequency by which people discuss politics. If we look at the discussion of substantive issues, the prospects for democratic discussion may be even gloomier.

More generally, we drive attention to the fact that the experience of one's network - and therefore one's reporting on that network - may in fact differ from the objective network. This difference can arise from the intentional withholding of information by network members. In this instance, the withholding is an attempt to avoid conflict. This work broadens the existing sociological work on selective disclosure from employing it in an attempt to manage stigma (Goffman 1963; Lee 1969; Shelley et al 1995; Cowan 2014) to employing it to manage interpersonal conflict. We contribute theoretically and substantively to two literatures in sociology: discussion networks, social selection and interpersonal influence; and public opinion polarization.

\section{Limitations and Future Research}

Despite the study's strengths, it has its limitations. Each is an opportunity for future research. We capture data from the Jameses and Walters to call upon our first example; the people in a dyadic political discussion who react to the initiation of a political discussion. While we learn quite a bit about political discussions from this vantage point, the other roles and dynamics go unexplored. Moving from the most micro to the macro, we begin with the initiators

- the Susans. In particular we do not know why she initiated the conversation, though the 
answers to our open-ended questions provide evidence for possible mechanisms: assumed agreement (which may have been the result of hearing second or third hand about a discussion partner's attitude), an external trigger that facilitated the conversation such as a news story, a personal event such as the loss of health insurance or being rejected for a job. Having initiated the conversation and perhaps been on the receiving end of selective non-disclosure, we do not fully know how initiators interpret non-response. Existing research suggests that they are likely to assume, at times erroneously, that their discussion partners agree with them. They do this in part by stereotyping based on their acquaintances' known characteristics and in part by projecting their own opinions (Goel, Mason and Watts 2010.) Just as it is possible that initiators learn from others' about their discussion partner's opinions prior to initiating, they may learn subsequently and that communication will also be subject to bias (Brashears and Gladstone 2016).

Our network generator questions presented two more limitations. First, by limiting the network to a maximum of ten potential political discussion partners, we may have artificially curtailed respondents networks if they have particularly large political discussion networks. We do not know the patterns in who they may have included or excluded, nor how that might affect selective disclosure. Second, while we capture political discussions among people who know each other's names, we do not capture those among strangers; this is a particularly interesting avenue for future research because selective disclosure and influence processes may work differently among those who do not know each other. Our data collection, furthermore, was equipped to document selective disclosure. Answers to the open-ended questions provide insights into other mechanisms to explain how and when people do and do not engage in political conversation which should be further examined. 
Human interactions are embedded in relational patterns that go well beyond the dyads we examine here. Further research should investigate how various network characteristics may enhance or decrease individuals' tendency to selectively disclose their political views. Some insights from the work presented here are suggestive of these relationships. For instance, prior research indicated that individuals in higher density networks are more likely to accurately perceive the attitudes of others within that network (Goel, Mason and Watts 2010). Our research here demonstrates that individuals are more likely to disclose their opinions when they know their discussion partner's opinion. Taken together, we would anticipate denser networks to have higher rates of disclosure overall but this should be investigated in future research.

Lastly, while in the following paragraphs we speculate about the macro-consequences of selective disclosure, the empirics presented here do not definitively demonstrate the macro consequences. We draw upon existing research to strengthen this argument, but we note that this area is a particularly worthwhile future endeavor.

\section{Conclusion}

Selective disclosure results in a biased experience that has real consequences. In our introduction we highlighted how it may affect dynamics of interpersonal influence, fostering polarization. In fact, selective disclosure and the resulting biased experience can have real consequences on the overall distribution of opinions. To the extent that voicing one's opinion affects other people's views, it matters whether all views in a social network are voiced, or only some (Noelle-Neumann 1984). It is plausible to expect that the experience of a homogeneous network might lead individuals to strengthen their views, through a mechanism of mutual reinforcement. 
However, selective disclosure may also be implicated in the reproduction of the social structure, reinforcing the effects of structural and choice homophily in political discussion networks. This is largely not attended to in studies of social selection and interpersonal influence. The most interesting aspect of selective disclosure is the disjuncture between its attempt at preventing conflict at the micro-level, and the perception of a greatly polarized society that it projects at the macro-level. This paradox may help make sense of the gap between perceived and real level of ideological polarization in the U.S. (Baldassarri and Bearman 2007). Following the sharp polarization of Congress, parties, and activists that occurred in the last three decades (Abramowitz \& Saunders 1998, Bartels 2000, Saunders \& Abramovitz 2004, Fiorina \& Abrams 2008, Fiorina et al 2005, Hetherington 2001, Levendusky 2009, McCarty, Poole \& Rosenthal 2006), scholars have turned their attention to public opinion, asking whether ordinary Americans have become more divided in their political views. While pundits and popular perceptions of public opinion polarization indicate that U.S. citizens are greatly divided over politics (Van Boven, Judd and Sherman 2012), empirical analyses of actual trends in public opinion show that Americans have diverged only on an handful of issues, among which federal spending and civil rights, but have remained stable, or even converged, on the majority of political issues (DiMaggio et al. 1996, Evans 2003, Fischer and Hout 2006, Baldassarri and Gelman 2009).

The gap between experience and reality may be greatly alimented by the patterns of selective disclosure that we have documented here. By revealing their political opinions mainly to likeminded discussion partners, individuals produce the experience of highly homogeneous social contexts, in which political agreement is over-estimated, and only one-sided views are voiced. Since election results and the public debate constantly remind us that there is also 'another, opposite side', U.S. citizens are induced to perceive the country as divided between 
'us' and 'them', thus highly polarized. This argument applies both to political partisanship and, more pervasively, as documented in this research, to specific political issues. Recent scholarship has shown that almost a third of U.S. citizens have conflicting views on moral and economic issues (Baldassarri and Goldberg 2014). Very likely, their discussion partners are not aware of these incongruences, thus fostering our misperception of a public opinion that is as polarized as parties and candidates are.

Were they aware of the persistence of disagreement in their local networks, and had they experienced more nuanced, two-sided conversations, they would probably have a less divided view of American society. Paradoxically, the mechanism of selective disclosure, whose goal is to prevent conflict at the micro-level, may lead to biased inferences of greater division in the larger society. 


\section{References:}

Abramowitz, Alan \& Kyle Saunders. 1998. "Ideological Realignment in the U.S. Electorate." The Journal of Politics 60(3):634-652.

Acock, Alan and Jeanne Hurlbert. 1993. "Social Networks, Marital Status, and Well-being." Social Networks 15(3):309-34.

Arendt, Hannah. 1968. The Origins of Totalitarianism. San Diego: Harcourt Brace Jovanovich.

Armstrong, E., P. England, and A. Fogarty. 2012. "Accounting for Women's Orgasm and Sexual Enjoyment in College Hookups and Relationships." American Sociological Review 77(3):435-62.

Baldassarri, Delia. 2012. The Simple Art of Voting: The Cognitive Shortcuts of Italian Voters. Oxford University Press.

Baldassarri, Delia. 2009. "Social Networks, Political Heterogeneity, and Interpersonal Influence. Evidence from the 2006 Italian Elections," APSA conference paper.

Baldassarri, Delia, and Peter Bearman. 2007. "Dynamics of Political Polarization." American Sociological Review. 72: 784-811.

Baldassarri, D. and A. Gelman. 2008. "Partisans Without Constraint: Political Polarization and Trends in American Public Opinion," American Journal of Sociology, 114(2): 408-46.

Bartels, Larry 2000. "Partisanship and Voting Behavior, 1952-1996." American Journal of Political Science 44(1):35-50.

Bearman, Peter and Paolo Parigi. 2004. "Cloning Headless Frog and Other Important Matters" Social Forces, 83 (2):535-557.

Beck, Paul, Russell Dalton, Steven Greene, and Robert Huckfeldt. 2002. "The Social Calculus of Voting: Interpersonal, Media, and Organizational Influences on Presidential Choices." American Political Science Review 96(01):57-73.

Berelson, B., Lazarsfeld, P., McPhee, W. 1954. Voting: A Study of Opinion Formation in a Presidential Election. Chicago: University of Chicago Press.

Brashears, Matthew. 2011. "Small Networks and High Isolation? A Reexamination of American Discussion Networks." Social Networks 33(4):331-41.

Brashears, Matthew E. 2014. "“Trivial' Topics and Rich Ties: The Relationship Between Discussion Topic, Alter Role, and Resource Availability Using the 'Important Matters' Name Generator." Sociological Science 1: 493-511.

Brashears, Matthew E., and Eric Gladstone. "Error Correction Mechanisms in Social Networks Can Reduce Accuracy and Encourage Innovation." Social Networks 44 (2016): 22-35.

Buhrmester, Michael, Tracy Kwang, and Samuel Gosling. 2011. "Amazon's Mechanical Turk A New Source of Inexpensive, Yet High-Quality, Data?” Perspectives on Psychological Science 6(1):3-5.

Carpini, Michael X. Delli, and Scott Keeter. 1993. "Measuring Political Knowledge: Putting First Things First.” American Journal of Political Science 1179-1206.

Converse, Phillip. 1964. "The Nature of Belief Systems in Mass Publics." in Ideology and Discontent, edited by David Apter. New York: Free Press.

Cowan, Sarah K. 2014. "Secrets and Misperceptions: The Creation of Self-Fulfilling Illusions" Sociological Science 1: 466-492.

Dahl, Robert A. 1961. Who Governs? Democracy and Power in an American City. New Haven: Yale University Press.

Dailey, R. M., \& Palomares, N. A. (2004). “Strategic Topic Avoidance: An Investigation of Topic Avoidance Frequency, Strategies Used, and Relational Correlates." 
Communication Monographs, 71, 471-496.

DiMaggio, Paul, John Evans, and Bethany Bryson. 1996. "Have Americans' Social Attitudes Become More Polarized?” American Journal of Sociology 102:690-755.

DiPrete, T., A. Gelman, T. McCormick, J. Teitler, and T. Zheng. 2011. "Segregation in Social Networks Based on Acquaintanceship and Trust." American Journal of Sociology.

Eriksson, K., and B. Simpson. 2012. "What Do Americans Know About Inequality? It Depends on How You Ask Them." Judgment and Decision Making 7(6):741-45.

Evans, John W. 2003. "Have Americans' Attitudes Become More Polarized?—An Update." Social Science Quarterly 84:71-90.

Fiorina, Morris P., and Samuel Abrams. 2008. "Political Polarization in the American Public." Annual Review of Political Science. 11:563-88.

Fiorina, Morris P., with Samuel Abrams and Jeremy C. Pope. 2005. Culture Wars? The Myth of Polarized America. New York: Pearson Longman.

Fischer, Claude and Michael Hout. 2006. Century of Difference. How America Changed in the Last One Hundred Years. New York: Russell Sage Foundation.

Fischer, Claude 2009. "The 2004 GSS Finding of Shrunken Social Networks: An Artifact?" American Sociological Review 74(4):657-69.

Fischer, Claude. 1982. To Dwell Among Friends: Personal Networks in Town and City. University of Chicago Press.

Gelman, Andrew, Sharad Goel, Douglas Rivers, David Rothschild, and others. 2016. "The Mythical Swing Voter.” Quarterly Journal of Political Science 11(1):103-30.

Gerber, Alan, and Donald Green. 2000. "The Effects of Canvassing, Telephone Calls, and Direct Mail on Voter Turnout: A Field Experiment." American Political Science Review 653-63.

Gerber, Alan, Gregory Huber, David Doherty, and Conor Dowling. 2012. "Disagreement and the Avoidance of Political Discussion: Aggregate Relationships and Differences Across Personality Traits." American Journal of Political Science 56(4):849-74.

Gibson, David R. "Enduring Illusions: The Social Organization of Secrecy and Deception." Sociological Theory Forthcoming.

Gigerenzer, Gerd, and Wolfgang Gaissmaier. 2011. "Heuristic Decision Making." Annual review of psychology 62:451-82.

Gigerenzer, G., Hertwig, R., Pachur, T. 2011. Heuristics: The foundations of adaptive behavior. New York: Oxford University Press.

Goffman, Erving. (1963) 1986. Stigma: Notes on the Management of Spoiled Identity. New York: Touchstone.

Goel, S., Obeng, A., \& Rothschild, D. (2015). Non-representative surveys: Fast, cheap, and mostly accurate. Working paper . Retrieved from http://researchdmr.com/FastCheapAccurate

Goel, S., Mason, and D. Watts. 2010. "Real and perceived attitude agreement in social networks." Journal of personality and social psychology 99(4):611.

Granovetter, M. (1973). The strength of weak ties. American Journal of Sociology, 78, 13601380.

Habermas, Jurgen. 1996. The Inclusion of the Other: Studies in Political Theory (Studies in Contemporary German Social Thought). The MIT Press. 
Hayes, Andrew, Carroll Glynn, and James Shanahan. 2005. "Willingness to Self-censor: A Construct and Measurement Tool for Public Opinion Research." International Journal of Public Opinion Research 17(3):298-323.

Hetherington, Marc 2001. "Resurgent Mass Partisanship: The Role of Elite Polarization." American Political Science Review. 95: 619-31.

Hibbing, John, and Elizabeth Theiss-Morse. 2002. Stealth Democracy: Americans' Beliefs About How Government Should Work. Cambridge University Press.

Hinton, Devon, Angela Nickerson, and Richard Bryant. 2011. "Worry, Worry Attacks, and PTSD Among Cambodian Refugees: A Path Analysis Investigation.” Social Science \& Medicine 72(11):1817-25.

Horton, J., D. Rand, and R. Zeckhauser. 2011. "The Online Laboratory: Conducting Experiments in a Real Labor Market." Experimental Economics 14(3):399-425.

Huckfeldt, R., Johnson, P., Sprague, J. 2004. Political Disagreement. The Survival of Diverse Opinions within Communication Networks. Cambridge: Cambridge University Press.

Huckfeldt, R., K. Ikeda, and F. U. Pappi. 2005. "Patterns of Disagreement in Democratic Politics: Comparing Germany, Japan, and the United States." American Journal of Political Science 49(3):497-514.

Huckfeldt, Robert, and Jeanette Morehouse Mendez. 2008. "Moths, Flames, and Political Engagement: Managing Disagreement Within Communication Networks." Journal of Politics 70(1):83-96.

Huckfeldt, R., Sprague, J. 1995. Citizens, Politics and Social Communication: Information and Influence in a Election Campaign. New York: Cambridge University Press.

Huckfeldt, Robert. 2007 "Unanimity, Discord, and the Communication of Public Opinion", American Journal of Political Science. 51(4): 978-995

Huckfeldt, Robert. 2001. "The Social Communication of Political Expertise." American Journal of Political Science 425-38.

Inskeep, Steve "Asking For Quiet: How To Defuse Thanksgiving Spats" National Public Radio. November 24, 2011.

Ipeirotis, P. 2010. "Demographics of Mechanical Turk." Social Science Research Network Working Paper (http://papers.ssrn.com/sol3/papers.cfm?abstract_id=1585030).

Jackman, Simon, and Paul M. Sniderman. 2006. "The Limits of Deliberative Discussion: A Model of Everyday Political Arguments." Journal of Politics 68(2):272-83.

Katz, Elihu and Paul Lazarsfeld. 1955. Personal Influence. Glencoe, IL: Free Press.

Keeter, Scott, Courtney Kennedy, Michael Dimock, Jonathan Best, and Peyton Craighill. 2006. "Gauging the Impact of Growing Nonresponse on Estimates from a National RDD Telephone Survey." Public Opinion Quarterly 70(5):759-79.

Kitts, James. 2003. "Egocentric Bias or Information Management? Selective Disclosure and the Social Roots of Norm Misperception." Social Psychology Quarterly, 66(3), 222-237.

Klofstad, Casey 2007. "Talk Leads to Recruitment How Discussions About Politics and Current Events Increase Civic Participation.” Political Research Quarterly 60(2):180-91.

Klofstad, Casey, Anand Sokhey, and Scott McClurg. 2013. "Disagreeing About Disagreement: How Conflict in Social Networks Affects Political Behavior." American Journal of Political Science, 57: 120-134.

Knobloch, L., \& Carpenter-Theune, K. (2004). “Topic Avoidance in Developing Romantic Relationships: Associations with Intimacy and Relational Uncertainty." Communication Research, 31, 173-205. 
Laumann, E. O. 1969. "Friends of urban men: An assessment of accuracy in reporting their socioeconomic attributes, mutual choice, and attitude agreement." Sociometry 32(1):5469.

Lazer, David, Brian Rubineau, Carol Chetkovich, Nancy Katz, and Michael Neblo. 2010. "The Coevolution of Networks and Political Attitudes." Political Communication 27(3):24874.

Lazarsfeld, P., Berelson, B., Gaudet, H. 1948. The People's Choice. New York: Columbia University Press.

Lee, Byungkyu, and Peter Bearman. 2017. "Important Matters in Political Context." Sociological Science 4: 1-30.

Lee, N. H. 1969. The search for an abortionist. University of Chicago Press Chicago IL

Levendusky, Matthew. 2009. The Partisan Sort: How Liberals Became Democrats and Conservatives Became Republicans. University of Chicago Press.

Luskin, Robert, James Fishkin, and Roger Jowell. 2002. "Considered Opinions: Deliberative Polling in Britain." British Journal of Political Science 32(3):455-87.

Lipset, Seymour M. 1996. American Exceptionalism: A Double-Edged Sword. New York: W. W. Norton).

Lipset, Seymour M. and Stein Rokkan 1967. "Cleavage Structures, Party System and Voter Alignments. An Introduction" pp. 1-64, edited by S. M. Lipset and S. Rokkan, Party System and Voter Alignments. New York: Free Press.

Marin, Alexandra 2004. "Are respondents more likely to list alters with certain characteristics?: Implications for name generator data", Social Networks 26 (4), 289-307.

Marsden, Peter and Karen Campbell. (1984). Measuring tie strength. Social Forces, 63, 482501.

Marsden, Peter 1987. "Core Discussion Networks of Americans." American Sociological Review $122-31$.

Mason, W., and S. Suri. 2012. "Conducting Behavioral Research on Amazon's Mechanical Turk." Behavior Research Methods 44(1):1-23.

McCarty, Nolan, Keith Poole, and Howard Rosenthal. 2006. Polarized America: The Dance of Ideology and Unequal Riches. Cambridge, MA: MIT Press.

McPherson, Miller, Lynn Smith, and James Cook. 2001. "Birds of a Feather: Homophily in Social Networks." Annual Review of Sociology (27):415-44.

McPherson, M., L. Smith-Lovin, and M. Brashears. 2006. "Social Isolation in America: Changes in Core Discussion Networks over Two Decades." American Sociological Review 71(3):353-75.

McPherson, Miller, Lynn Smith-Lovin, and Matthew Brashears. 2008. "Social Isolation in America: Changes in Core Discussion Networks over Two Decades." American Sociological Review 73(6):1022-1022.

McPherson, Miller, Lynn Smith-Lovin, and Matthew Brashears. 2009. "Models and Marginals: Using Survey Evidence to Study Social Networks." American Sociological Review 74(4):670-81.

Mendelberg, Tali. 2002. "The Deliberative Citizen: Theory and Evidence.” Political Decision Making, Deliberation and Participation 6(1):151-93.

Mill, John Stuart. 1859. On Liberty. J. W. Parker and Son.

Moore, Gwen. 1990. "Structural Determinants of Men's and Women's Personal Networks." American Sociological Review 726-35. 
Mutz, Diana 2002a. "Cross-cutting social networks: Testing Democratic Theory in Practice". American Political Science Review. 96 (1): 111-126.

Mutz, Diana 2002b. "The Consequences of Cross-cutting Networks for Political Participation". American Journal of Political Science. 46 (4): 838-855.

Mutz, Diana 2006. Hearing the Other Side: Deliberative vs. Participatory Democracy. Cambridge: Cambridge University Press.

Mutz, Diana C., and Jeffery J. Mondak. 2006. "The Workplace as a Context for Cross-Cutting Political Discourse." Journal of Politics 68(1):140-55.

Nickerson, David W. 2008. "Is Voting Contagious? Evidence from Two Field Experiments." American Political Science Review 102(1):49.

Nunn, C., H. Crockett, and J. Williams. 1978. Tolerance for nonconformity. Jossey-Bass Publishers

Noelle-Neumann, Elisabeth. 1984. The Spiral of Silence: Public Opinion--Our Social Skin. 1st ed. University Of Chicago Press.

Paik, Anthony, and Kenneth Sanchagrin. 2013. "Social Isolation in America: An Artifact." American Sociological Review 78(3):339-60.

Paolacci, G., J. Chandler, and P. Ipeirotis. 2010. "Running Experiments on Amazon Mechanical Turk." Judgment and Decision Making 5(5):411-19.

Parker, Suzanne, Glenn Parker, and James McCann. 2008. "Opinion Taking Within Friendship Networks." American Journal of Political Science 52(2):412-20.

Robbins, J, and J. Krueger. 2005. "Social projection to ingroups and outgroups: A review and meta-analysis." Personality and Social Psychology Review 9(1):32-47.

Rothschild, David, Goel Sharad, Andrew Gelman and Doug Rivers. 2014. "The Mythical Swing Voter." Conference Presentation at Human Computation. Cambridge, MA. June 10-12.

Saunders, Kyle and Alan Abramowitz. 2004. "Ideological Realignment and Active Partisans in the American Electorate." American Politics Research 32:285-309.

Schroder, K., M. Carey, and P. Vanable. 2003. "Methodological challenges in research on sexual risk behavior: II. Accuracy of self-reports." Annals of Behavioral Medicine 26(2):104123

Shelley, Gene, H. Russell Bernard, Peter Killworth, Eugene Johnsen, and Christopher McCarty. July 1995. "Who knows your HIV status? What HIV + patients and their network members know about each other." Social Networks 17(3-4):189-217.

Singleton, Jr, Royce A. and Bruce C. Straits. 2005. Approaches to Social Research. 4th edition. New York: Oxford University Press.

Small, Mario. 2013. "Weak Ties and the Core Discussion Network: Why People Regularly Discuss Important Matters with Unimportant Alters." Social Networks 35(3):470-83.

Sprouse, J. 2011. "A Validation of Amazon Mechanical Turk for the Collection of Acceptability Judgments in Linguistic Theory." Behavior Research Methods 43(1):155-67.

Stouffer, S.A. 1992 [1955]. Communism, conformity, and civil liberties: A cross-section of the nation speaks its mind. Transaction Publishers.

Sunstein, C. 2009. Going to extremes: how like minds unite and divide. Oxford University Press, USA.

Verba, Sidney, Kay L. Schlozman, and Henry Brady 1995. Voice and Equality. Civic Voluntarism in American Politics. Cambridge: Harvard University Press.

Van Boven, L., Judd, C., \& Sherman, D. (2012). Perceiving political polarization: Social projection of attitude extremity and processes. Journal of Personality and Social 
Psychology, 103, 84-100.

Wanga, Wei, David Rothschildb, Sharad Goelb, and Andrew Gelman. 2014. "Forecasting Elections with Non-Representative Polls." International Journal of Forecasting. Forthcoming.

Willer, Robb, Christabel Rogalin, Bridget Conlon, and Michael Wojnowicz. 2013. "Overdoing Gender: A Test of the Masculine Overcompensation Thesis." American Journal of Sociology 118(4):980-1022.

Zaller, John. 1992. The Nature and Origins of Mass Opinion. New York: Cambridge University Press.

Zuckerman, Alan, ed. 2005. The Social Logic of Politics: Personal Networks as Contexts for Political Behavior. Philadelphia, PA: Temple University Press. 


\section{Tables and Figures}

Table 1: Sample Characteristics

\begin{tabular}{|c|c|}
\hline \multicolumn{2}{|l|}{ Age } \\
\hline $18-25$ & 26.4 \\
\hline $25-35$ & 38.8 \\
\hline $35-45$ & 15.8 \\
\hline $45-55$ & 10.7 \\
\hline $55+$ & 8.3 \\
\hline \multicolumn{2}{|l|}{ Gender } \\
\hline Male & 42.8 \\
\hline Female & 57.2 \\
\hline \multicolumn{2}{|l|}{ Employment Status } \\
\hline Working as paid employee & 51.1 \\
\hline Self-employed & 18.2 \\
\hline Not working - looking for work & 22.8 \\
\hline Retired & 4.5 \\
\hline Disabled & 3.4 \\
\hline \multicolumn{2}{|l|}{ Religion } \\
\hline Protestant & 21.8 \\
\hline Catholic & 17.1 \\
\hline Other Christian & 16.0 \\
\hline Non-Christian & 9.5 \\
\hline None & 35.6 \\
\hline Evangelical & 18.1 \\
\hline \multicolumn{2}{|l|}{ Religious Service Attendance } \\
\hline Once a week or more & 17.1 \\
\hline Once or twice a month & 7.8 \\
\hline A few times a year & 15.1 \\
\hline Once a year or less & 17.8 \\
\hline Never & 42.2 \\
\hline \multicolumn{2}{|l|}{ Education } \\
\hline Less than high school & 1.6 \\
\hline High school graduate/GED & 12.7 \\
\hline Some college & 31.9 \\
\hline Associates degree & 10.5 \\
\hline Bachelor's Degree & 31.6 \\
\hline Graduate Degree & 11.8 \\
\hline \multicolumn{2}{|l|}{ Race } \\
\hline White & 79.5 \\
\hline Black & 8.6 \\
\hline Asian & 7.3 \\
\hline Other & 4.6 \\
\hline Hispanic & 6.7 \\
\hline \multicolumn{2}{|l|}{ Income } \\
\hline Less than $\$ 25 \mathrm{k}$ & 28.6 \\
\hline$\$ 25 \mathrm{k}-\$ 50 \mathrm{k}$ & 30.3 \\
\hline$\$ 50 \mathrm{k}-\$ 75 \mathrm{k}$ & 20.3 \\
\hline$\$ 75 \mathrm{k}-\$ 125 \mathrm{k}$ & 15.6 \\
\hline$\$ 125 \mathrm{k}$ & 5.2 \\
\hline \multicolumn{2}{|l|}{ Urban Status } \\
\hline Rural & 12.7 \\
\hline Town & 24.7 \\
\hline Small City & 33.5 \\
\hline Large City & 29.1 \\
\hline \multicolumn{2}{|l|}{ Interest in Politics } \\
\hline Not much interested & 12.1 \\
\hline Somewhat interested & 49.9 \\
\hline Very interested & 38.0 \\
\hline
\end{tabular}


Figure 1: Selective Disclosure
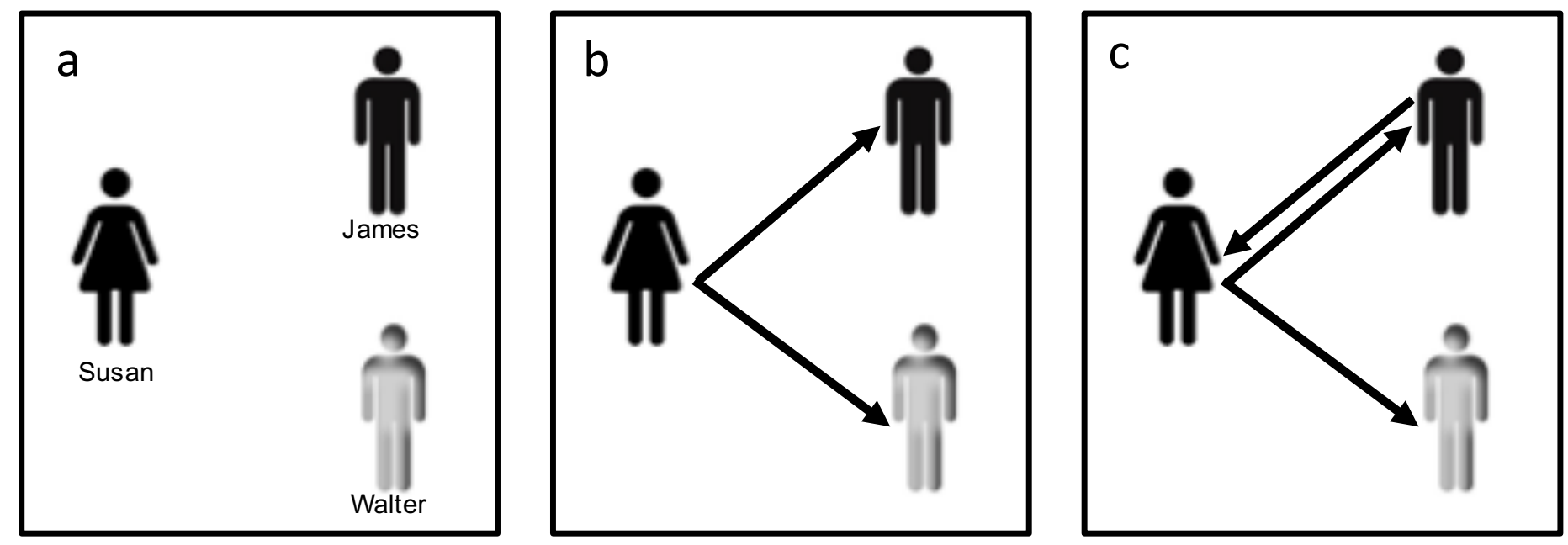
Figure 2: Rates of disclosure of political party affiliation and opinions on specific issues across all discussion partners

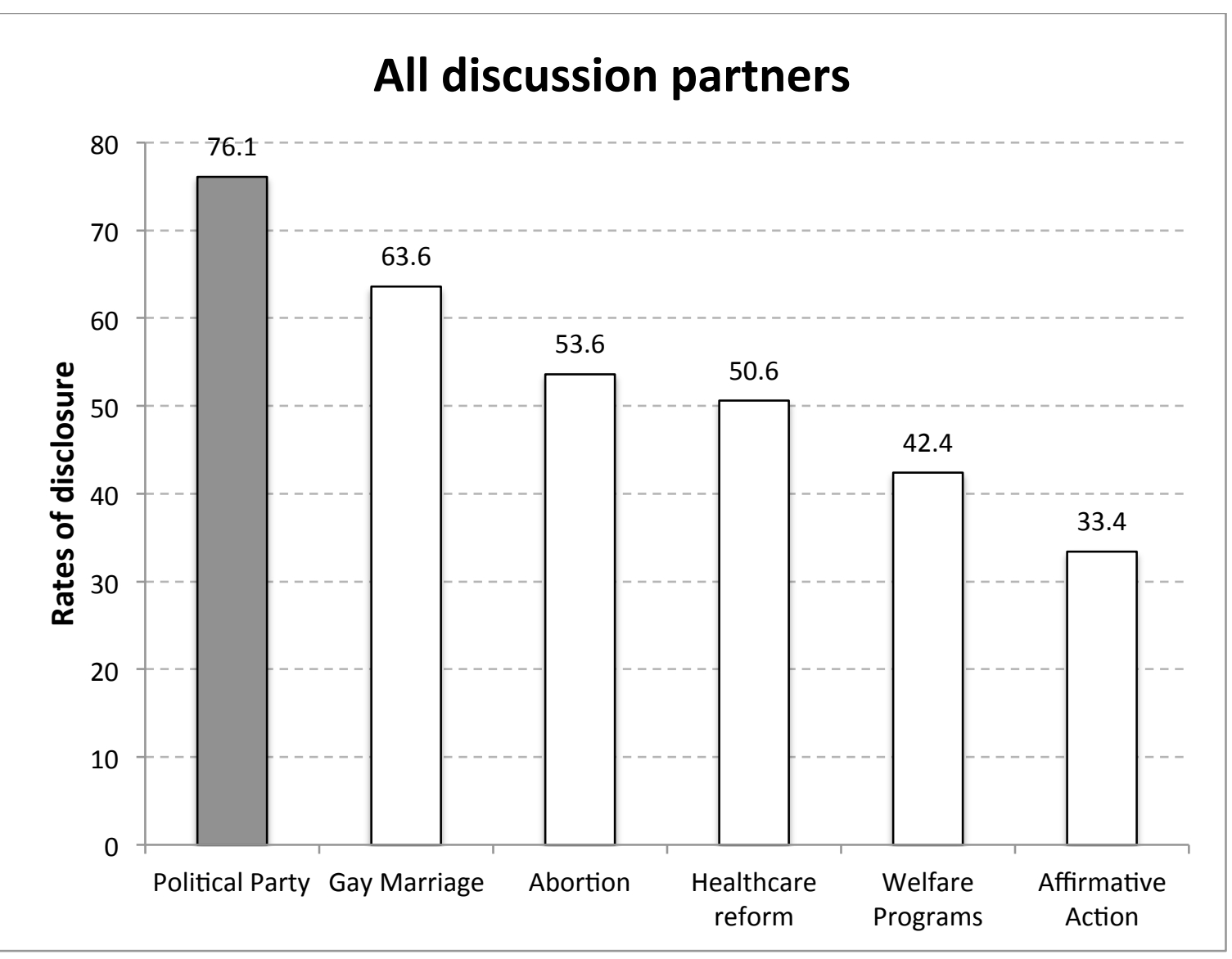


Figure 3: Rates of disclosure of political party affiliation and opinions on specific issues by type of discussant.

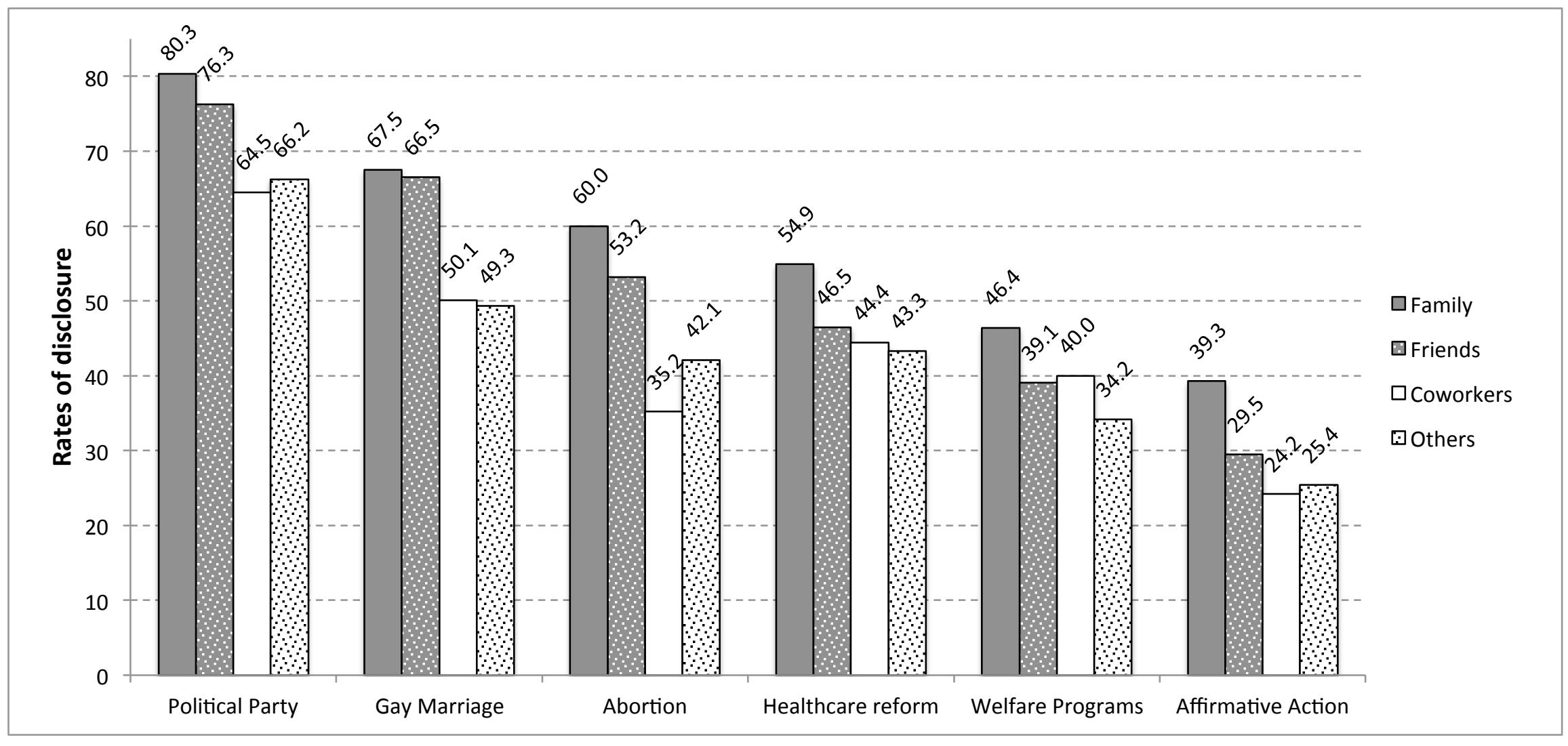


Figure 4: Rates of disclosure of political party affiliation and opinions on specific issues by whether egos know and agree with their discussion partners

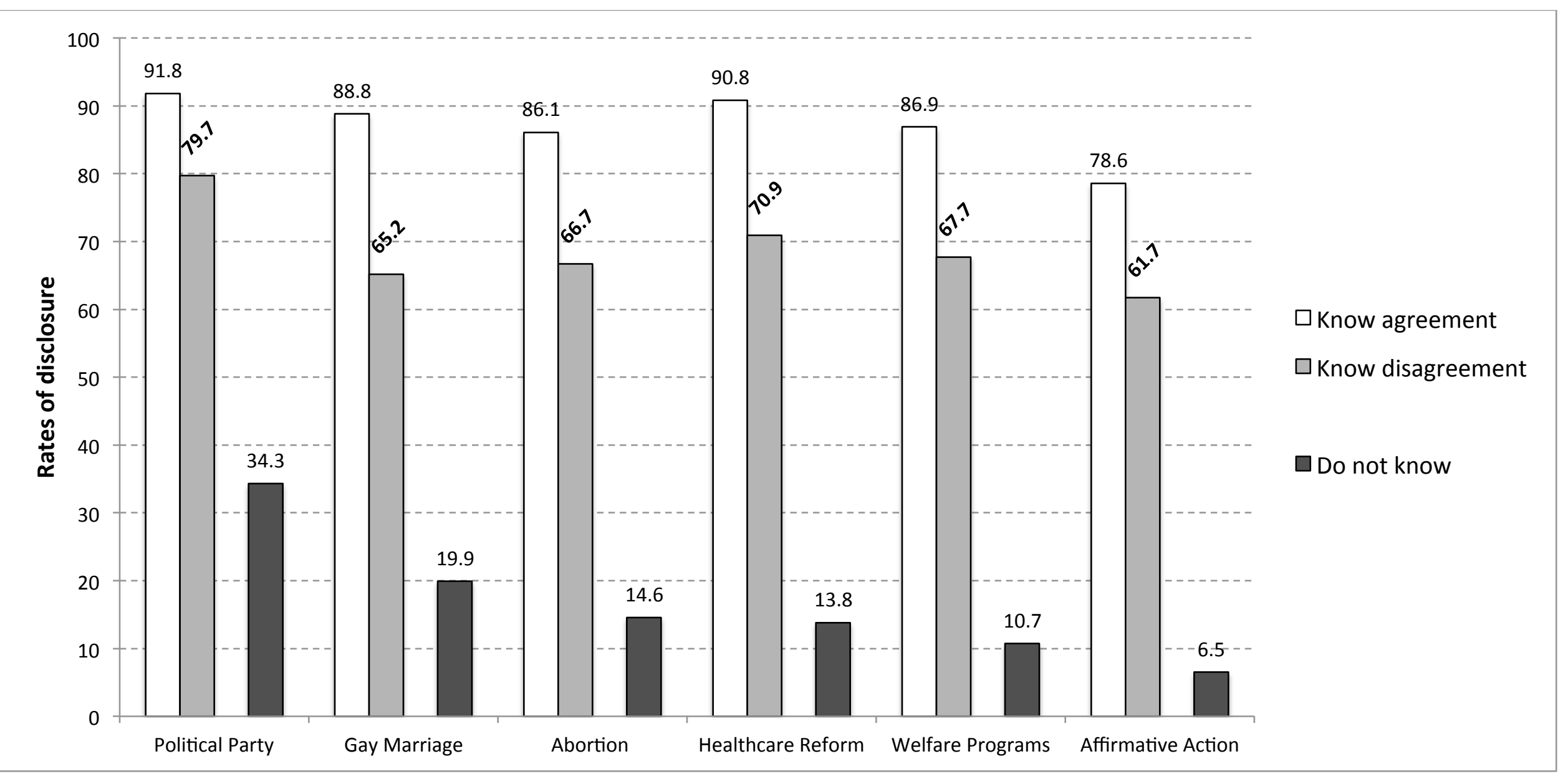


Table 2: Logistic Regressions of Disclosure on Dyad, Discussion and Respondent Characteristics, Odds-Ratio

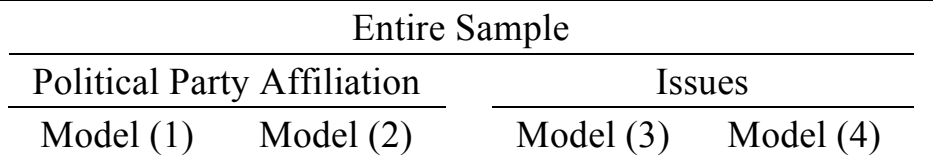

Knowledge of Alter's Political View

Agreement

Issue (ref is Welfare)

Abortion

Gay Marriage

Affirmative Action

Healthcare Reform

Relationship

Friends

Coworkers

Other

Interest in Politics (ref is not much interested)

Somewhat interested

Very interested

Ideology (ref is extremely liberal)

Liberal
$12.1 * * *$

(1.37)

$29.7 * * *$

(1.67)

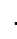

$--$

$-$

$0.71 * *$

(0.078)

$0.35 * * *$

(0.050)

$0.44 * * *$

(0.063)

0.93

(0.11)

$0.48 * * *$

(0.082)

$0.54 * * *$

(0.089)

$1.27 \quad 1.24$

(0.28)

$1.67 *$

(0.39)

(0.30)

$1.64^{*}$

(0.41)

0.84

0.87

$0.76 * * *$

(0.042)

$0.50 * * *$

0.89

(0.058)

$0.69 * * *$

(0.043)

$0.52 * * *$

(0.061)

$0.58 * * *$

(0.055)

(0.041)

1.19

1.13

(0.13)

(0.16)

$1.56 * * *$

$1.49 * *$

(0.18)

(0.20)

$0.67 * * * \quad 0.74 * *$

$--$

$\begin{array}{cc}1.68 * * * & 1.27 * * * \\ (0.088) & (0.083) \\ 2.62 * * * & 1.60 * * * \\ (0.15) & (0.11) \\ 0.67 * * * & 0.63 * * * \\ (0.034) & (0.039) \\ 1.48 * * * & 1.44 * * * \\ (0.069) & (0.088)\end{array}$

\begin{tabular}{l} 
Respondent Knows Alt \\
\hline Political Party Affiliation \\
\hline Model (5) Model (6)
\end{tabular}

$--$

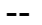

$--$

$-$

$2.79 * * *$

(0.33)

$3.46 * * *$

$(0.22)$

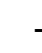

$-$

1.15
$--$

$--$

$--$

$--$

(0.11)

$0.64 * * *$

$(0.048)$

$1.42 * * *$

(0.12)

1.07

(0.087)

$0.50 * * *$

(0.041)

$1.30 * *$

(0.11)

$\begin{array}{cc}0.95 & 1.02 \\ (0.13) & (0.15) \\ 0.38 * * * & 0.43 * * * \\ (0.070) & (0.081) \\ 0.47 * * * & 0.52 * * * \\ (0.084) & (0.098)\end{array}$

1.07

(0.092)

1.05

$0.58 * * * \quad 0.64 * * *$

(0.063)

(0.071)

$\begin{array}{cccc}1.12 & 1.07 & 1.21 & 1.34 \\ (0.30) & (0.29) & (0.20) & (0.22) \\ 1.64 & 1.55 & 1.58 * * & 1.70 * * \\ (0.46) & (0.43) & (0.27) & (0.29)\end{array}$

$0.74 \quad 0.78$

$0.74 *$

0.82
(0.11) (0.11) 


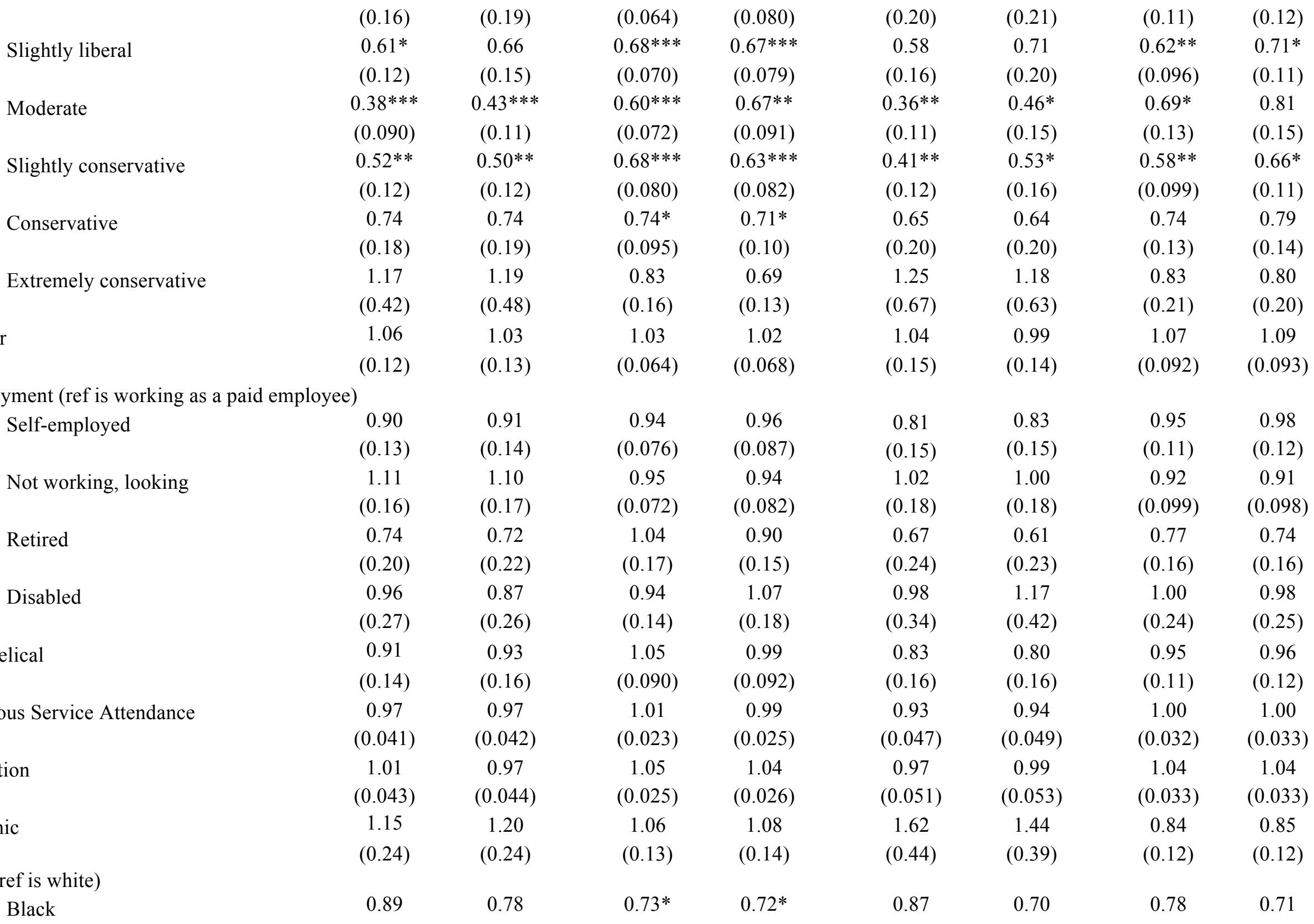




\begin{tabular}{|c|c|c|c|c|c|c|c|c|}
\hline & $(0.19)$ & $(0.18)$ & $(0.091)$ & $(0.092)$ & $(0.24)$ & $(0.20)$ & $(0.13)$ & $(0.13)$ \\
\hline \multirow[t]{2}{*}{ Asian } & $0.44 * * *$ & $0.49 * * *$ & $0.68 * *$ & 0.93 & $0.56^{*}$ & $0.48^{* *}$ & 0.88 & 0.88 \\
\hline & $(0.094)$ & $(0.10)$ & $(0.095)$ & $(0.12)$ & $(0.13)$ & $(0.11)$ & $(0.14)$ & $(0.14)$ \\
\hline \multirow[t]{2}{*}{ Other } & 0.73 & 0.83 & 1.07 & 1.00 & 0.75 & 0.78 & 1.00 & 1.03 \\
\hline & $(0.19)$ & $(0.23)$ & $(0.16)$ & $(0.15)$ & $(0.25)$ & $(0.26)$ & $(0.17)$ & $(0.18)$ \\
\hline \multirow[t]{2}{*}{ Income } & 1.00 & 1.00 & 1.00 & 0.99 & 1.01 & 1.01 & 0.98 & 0.98 \\
\hline & $(0.015)$ & $(0.016)$ & $(0.0081)$ & $(0.0083)$ & $(0.018)$ & $(0.018)$ & $(0.010)$ & $(0.010)$ \\
\hline \multicolumn{9}{|c|}{ Marital Status (ref is married) } \\
\hline \multirow[t]{2}{*}{ Widowed } & 0.55 & 0.45 & 0.86 & 1.00 & 0.44 & 0.57 & 0.98 & 0.89 \\
\hline & $(0.31)$ & $(0.27)$ & $(0.17)$ & $(0.21)$ & $(0.30)$ & $(0.37)$ & $(0.27)$ & $(0.24)$ \\
\hline \multirow{2}{*}{ Divorced } & 0.82 & 1.08 & 1.11 & 1.19 & 0.99 & 0.98 & 1.16 & 1.16 \\
\hline & $(0.19)$ & $(0.27)$ & $(0.15)$ & $(0.16)$ & $(0.28)$ & $(0.28)$ & $(0.21)$ & $(0.21)$ \\
\hline \multirow[t]{2}{*}{ Separated } & 0.64 & 0.63 & 0.88 & 0.94 & 0.79 & 0.58 & 1.03 & 0.96 \\
\hline & $(0.30)$ & $(0.30)$ & $(0.37)$ & $(0.37)$ & $(0.46)$ & $(0.35)$ & $(0.54)$ & $(0.54)$ \\
\hline \multirow[t]{2}{*}{ Never Married } & 0.90 & 0.93 & $0.83 *$ & 0.91 & 0.86 & 0.87 & 0.86 & 0.91 \\
\hline & $(0.12)$ & $(0.14)$ & $(0.065)$ & $(0.078)$ & $(0.14)$ & $(0.15)$ & $(0.095)$ & $(0.10)$ \\
\hline \multirow[t]{2}{*}{ Cohabitating } & 0.93 & 0.97 & 1.03 & 1.06 & 0.92 & 0.94 & 1.09 & 1.13 \\
\hline & $(0.15)$ & $(0.18)$ & $(0.094)$ & $(0.11)$ & $(0.20)$ & $(0.20)$ & $(0.15)$ & $(0.15)$ \\
\hline \multicolumn{9}{|c|}{ Urban Status (ref is rural) } \\
\hline \multirow[t]{2}{*}{ Town } & 1.08 & 1.07 & 0.83 & 0.84 & 1.06 & 1.11 & 0.89 & 0.90 \\
\hline & $(0.19)$ & $(0.22)$ & $(0.091)$ & $(0.098)$ & $(0.25)$ & $(0.26)$ & $(0.13)$ & $(0.13)$ \\
\hline \multirow[t]{2}{*}{ Small City } & 1.12 & 1.10 & 0.82 & 0.90 & 1.11 & 1.10 & 0.94 & 0.96 \\
\hline & $(0.19)$ & $(0.21)$ & $(0.086)$ & $(0.10)$ & $(0.24)$ & $(0.24)$ & $(0.14)$ & $(0.14)$ \\
\hline \multirow[t]{2}{*}{ Large City } & 1.07 & 0.91 & 0.89 & 0.96 & 0.91 & 0.91 & 1.07 & 1.09 \\
\hline & $(0.19)$ & $(0.18)$ & $(0.096)$ & $(0.11)$ & $(0.21)$ & $(0.20)$ & $(0.16)$ & $(0.16)$ \\
\hline \multirow[t]{2}{*}{ Age } & $1.01^{*}$ & 1.01 & 1.00 & 1.00 & 1.01 & 1.01 & 1.00 & 1.00 \\
\hline & $(0.0058)$ & $(0.0065)$ & $(0.0032)$ & $(0.0034)$ & $(0.0073)$ & $(0.0076)$ & $(0.0044)$ & $(0.0044)$ \\
\hline \multirow[t]{2}{*}{ Constant } & 3.82 & 0.93 & 0.71 & $0.13^{* * *}$ & $16.2 * *$ & $7.52^{*}$ & $3.07 *$ & 1.20 \\
\hline & $(2.63)$ & $(0.70)$ & $(0.25)$ & $(0.054)$ & $(14.0)$ & $(6.54)$ & $(1.59)$ & $(0.62)$ \\
\hline Observations & 4,148 & 4,144 & 22,877 & 22,850 & 3,499 & 3,499 & 12,312 & 12,312 \\
\hline Adjusted R-squared & .06 & .21 & .06 & .40 & .05 & .09 & .03 & .08 \\
\hline
\end{tabular}


Appendix: Weighting Procedures

Below is a description of how the weights were generated as well as a table describi the sample and another with the regression analyses for both the unweighted and one weigh sample. Encouragingly, while the sample composition changes with the weighting, the resu not in any substantive way. Largely, the coefficients in the regression analysis remain stabl while the standard errors increase; this is a feature of weighting (Winship and Radbill 1994 Skinner and Mason 2012). Thus, the results have proved themselves to be robust to change: the sample composition. We further test the robustness of the results to changes in sample composition by changing the inputs to the weighting function (details below).

We generated these weights using raking, an iterative procedure that matches the marginal distribution of selected variables to their marginal distribution in the population. Previous studies using survey data from non-probability samples (Yeager et al 2011) have $\mathrm{l}$ similar procedure to improve the match between sample and population.

Specifically, we used the 2012 General Social Survey (GSS) to calculate benchmark proportions of each of the following variables in the US population: region, sex, sex by age education, sex by education, race, Hispanic ethnicity, ideology, and political party identific: The weights generated by raking match the sample distribution of the above variables to the corresponding population distribution within a specified tolerance (here the sample and population distributions differ by less than 0.1 percentage points for each variable). We use $\mathrm{R}$ package anesrake (Pasek 2012) to perform the raking, which follows the raking recommendations set forth in DeBell and Krosnick (2009).

We used four different weighting functions utilizing different combinations of the a benchmarks. Prior to applying the weights to the data, we chose the one which had the sma variance (presented below). This weight weights according to region, sex by age, race, sex education, party identification and Hispanic ethnicity. We chose it before applying to the w so we would not be biased by the results. The results with the other weights are available ur request but they were not markedly different than these results. 
Table 1: Sample Characteristics

Unweighted Weighted

Age

$18-25$

26.4

11.6

25-35

38.8

19.2

$35-45$

15.8

18.4

45-55

10.7

31.4

$55+$

8.3

19.4

Gender

Male

42.8

46.0

Female

57.2

54.0

Employment Status

Working as paid employee

51.1

40.6

Self-employed

18.2

21.0

Not working - looking for work

22.8

25.4

Retired

4.5

6.5

Disabled

3.4

6.6

Religion

Protestant

21.8

28.0

Catholic

17.1

21.9

Other Christian

16.0

19.9

Non-Christian

9.5

6.7

None

35.6

23.5

Evangelical

18.1

23.6

Religious Service Attendance

Once a week or more

17.1

15.3

Once or twice a month

7.8

8.4

A few times a year

15.1

16.8

Once a year or less

17.8

20.3

Never

42.2

39.2

Education

Less than high school

1.6

12.7

7.7

High school graduate/GED

31.9

56.6

Some college

31.6

8.0

Bachelor's Degree

11.8

16.6

Graduate Degree

11.2

Race

White

79.5

73.6

Black

8.6

14.8

Asian

7.3

7.3

Other

11.9

11.6

Hispanic

6.7

15.2

Income

Less than $\$ 25 \mathrm{k}$

28.6

29.4

$\$ 25 \mathrm{k}-\$ 50 \mathrm{k}$

30.3

36.6

$\$ 50 \mathrm{k}-\$ 75 \mathrm{k}$

20.3

20.5 
$\$ 75 \mathrm{k}-\$ 125 \mathrm{k}$

$\$ 125 \mathrm{k}$

Urban Status

Rural

Town

Small City

Large City

Interest in Politics

Not much interested

Somewhat interested

Very interested
15.6

5.2

12.7

24.7

33.5

29.1

12.1

49.9

38.0
10.3

3.2

19.1

21.8

30.7

28.4

8.6

46.7

44.7 
Table 2a: Logistic Regression of Disclosure on Dyad, Discussion and Respondent Characteristics, Odds-Ratio

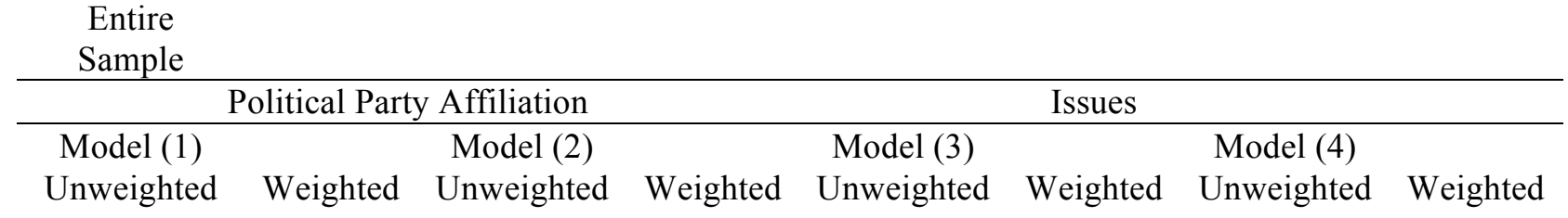

Agreement

--

$-$

Knowledge of Discussion Partner's Attitude

Issue (ref is Welfare)

Abortion

Gay Marriage

Affirmative Action

Healthcare Reform

Relationship

Friends

Coworkers

$0.71^{* *}$

(0.078)

Other

$0.35 * * *$

(0.050)

$0.44 * * *$

$(0.063)$

Interest in Politics (ref is not much interested)

Somewhat interested

$\begin{array}{cc}1.27 & 1.15 \\ (0.28) & (0.52) \\ 1.67^{*} & 1.55 \\ (0.39) & (0.71)\end{array}$

0.79

(0.19)

0.45

$(0.19)$

$0.45^{*}$

(0.16)

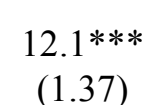

$7.90^{* * *}$

(1.37)

(2.12)

Very interested

$1.67^{*}$
$(0.39)$

(0.71)

0.93
$(0.11)$
$0.48^{* * *}$
$(0.082)$
$0.54^{* * *}$
$(0.089)$

1.24
$(0.30)$
$1.64 *$
$(0.41)$

0.90

$(0.24)$

0.62

(0.29)

$0.42 *$

$(0.17)$

$-$

$1.68 * * *$

$(0.088)$

$2.62 * * *$

$1.44^{* *}$

(0.18)

$2.34 * * *$

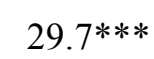

(1.67)

$42.6 * * *$

Ideology (ref is extremely

liheral) 


\begin{tabular}{|c|c|c|c|c|c|c|c|c|}
\hline \multirow{3}{*}{ Slightly liberal } & $(0.16)$ & $(1.84)$ & $(0.19)$ & $(1.25)$ & $(0.064)$ & $(0.28)$ & $(0.080)$ & $(0.22)$ \\
\hline & $0.61^{*}$ & 2.02 & 0.66 & 1.66 & $0.68 * * *$ & 1.00 & $0.67 * * *$ & 0.64 \\
\hline & $(0.12)$ & $(0.99)$ & $(0.15)$ & $(0.86)$ & $(0.070)$ & $(0.23)$ & $(0.079)$ & $(0.19)$ \\
\hline \multirow[t]{2}{*}{ Moderate } & $0.38 * * *$ & 1.09 & $0.43 * * *$ & 0.93 & $0.60 * * *$ & 1.21 & $0.67 * *$ & 0.79 \\
\hline & $(0.090)$ & $(0.53)$ & $(0.11)$ & $(0.46)$ & $(0.072)$ & $(0.30)$ & $(0.091)$ & $(0.25)$ \\
\hline \multirow[t]{2}{*}{ Slightly conservative } & $0.52 * *$ & 1.76 & $0.50 * *$ & 1.57 & $0.68 * * *$ & 1.57 & $0.63 * * *$ & 1.04 \\
\hline & $(0.12)$ & $(0.94)$ & $(0.12)$ & $(0.90)$ & $(0.080)$ & $(0.40)$ & $(0.082)$ & $(0.30)$ \\
\hline \multirow[t]{2}{*}{ Conservative } & 0.74 & $2.92 *$ & 0.74 & 2.50 & $0.74 *$ & $1.97 * *$ & $0.71 *$ & 1.11 \\
\hline & $(0.18)$ & $(1.52)$ & $(0.19)$ & $(1.28)$ & $(0.095)$ & $(0.46)$ & $(0.10)$ & $(0.40)$ \\
\hline \multirow[t]{2}{*}{ Extremely conservative } & 1.17 & $5.37^{*}$ & 1.19 & 3.69 & 0.83 & 1.80 & 0.69 & 0.79 \\
\hline & $(0.42)$ & $(3.51)$ & $(0.48)$ & $(2.61)$ & $(0.16)$ & $(0.57)$ & $(0.13)$ & $(0.29)$ \\
\hline \multirow[t]{2}{*}{ Gender } & 1.06 & $2.05^{* *}$ & 1.03 & $1.91^{*}$ & 1.03 & 1.35 & 1.02 & 1.11 \\
\hline & $(0.12)$ & $(0.56)$ & $(0.13)$ & $(0.56)$ & $(0.064)$ & $(0.21)$ & $(0.068)$ & $(0.18)$ \\
\hline \multicolumn{9}{|c|}{ Employment (ref is working as a paid employee) } \\
\hline \multirow[t]{2}{*}{ Self-employed } & 0.90 & 0.82 & 0.91 & 0.90 & 0.94 & $0.70 *$ & 0.96 & 0.88 \\
\hline & $(0.13)$ & $(0.26)$ & $(0.14)$ & $(0.31)$ & $(0.076)$ & $(0.13)$ & $(0.087)$ & $(0.19)$ \\
\hline \multirow{2}{*}{ Not working, looking } & 1.11 & 0.82 & 1.10 & 1.10 & 0.95 & $0.66^{*}$ & 0.94 & 0.84 \\
\hline & $(0.16)$ & $(0.27)$ & $(0.17)$ & $(0.38)$ & $(0.072)$ & $(0.12)$ & $(0.082)$ & $(0.16)$ \\
\hline \multirow[t]{2}{*}{ Retired } & 0.74 & 0.81 & 0.72 & 1.00 & 1.04 & 0.66 & 0.90 & 0.78 \\
\hline & $(0.20)$ & $(0.32)$ & $(0.22)$ & $(0.39)$ & $(0.17)$ & $(0.16)$ & $(0.15)$ & $(0.21)$ \\
\hline \multirow{2}{*}{ Disabled } & 0.96 & 0.50 & 0.87 & 0.48 & 0.94 & $0.51^{*}$ & 1.07 & 0.94 \\
\hline & $(0.27)$ & $(0.40)$ & $(0.26)$ & $(0.38)$ & $(0.14)$ & $(0.14)$ & $(0.18)$ & $(0.27)$ \\
\hline \multirow[t]{2}{*}{ Evangelical } & 0.91 & 0.88 & 0.93 & 0.93 & 1.05 & 0.92 & 0.99 & 0.80 \\
\hline & $(0.14)$ & $(0.27)$ & $(0.16)$ & $(0.32)$ & $(0.090)$ & $(0.17)$ & $(0.092)$ & $(0.14)$ \\
\hline \multirow[t]{2}{*}{ Religious Service Attendance } & 0.97 & 1.06 & 0.97 & 1.06 & 1.01 & 1.10 & 0.99 & 1.06 \\
\hline & $(0.041)$ & $(0.092)$ & $(0.042)$ & $(0.096)$ & $(0.023)$ & $(0.066)$ & $(0.025)$ & $(0.063)$ \\
\hline \multirow[t]{2}{*}{ Education } & 1.01 & 1.05 & 0.97 & 1.00 & 1.05 & 0.97 & 1.04 & 0.95 \\
\hline & $(0.043)$ & $(0.083)$ & $(0.044)$ & $(0.084)$ & $(0.025)$ & $(0.051)$ & $(0.026)$ & $(0.051)$ \\
\hline \multirow[t]{2}{*}{ Hispanic } & 1.15 & 0.88 & 1.20 & 1.16 & 1.06 & $0.68 *$ & 1.08 & $0.68 *$ \\
\hline & $(0.24)$ & $(0.34)$ & $(0.24)$ & $(0.44)$ & $(0.13)$ & $(0.13)$ & $(0.14)$ & $(0.13)$ \\
\hline \multicolumn{9}{|l|}{ Race (ref is white) } \\
\hline \multirow[t]{2}{*}{ Black } & 0.89 & 1.67 & 0.78 & 2.17 & $0.73 *$ & 1.20 & $0.72 *$ & 1.08 \\
\hline & $(0.19)$ & $(0.64)$ & $(0.18)$ & $(0.90)$ & $(0.091)$ & $(0.29)$ & $(0.092)$ & $(0.26)$ \\
\hline \multirow[t]{2}{*}{ Asian } & $0.44 * * *$ & $0.25 *$ & $0.49 * * *$ & $0.33^{*}$ & $0.68 * *$ & $0.48^{*}$ & 0.93 & $0.49^{*}$ \\
\hline & $(0.094)$ & $(0.15)$ & $(0.10)$ & $(0.17)$ & $(0.095)$ & $(0.16)$ & $(0.12)$ & $(0.14)$ \\
\hline Other & 0.73 & $3.57^{*}$ & 0.83 & $3.09^{*}$ & 1.07 & $1.99^{*}$ & 1.00 & $1.91 *$ \\
\hline
\end{tabular}


Income

Marital Status (ref is married)

Widowed

Divorced

Separated

Never Married

Cohabitating

Urban Status (ref is rural)

Town

Small City

Large City

Age

Constant

Observations

Adjusted R-squared

$* * * \mathrm{p}<0.001, * * \mathrm{p}<0.01, *$

$\mathrm{p}<0.05$

\begin{tabular}{cccccccc}
$(0.19)$ & $(2.05)$ & $(0.23)$ & $(1.69)$ & $(0.16)$ & $(0.55)$ & $(0.15)$ & $(0.61)$ \\
1.00 & 1.04 & 1.00 & 1.04 & 1.00 & 1.00 & 0.99 & 0.97 \\
$(0.015)$ & $(0.035)$ & $(0.016)$ & $(0.036)$ & $(0.0081)$ & $(0.020)$ & $(0.0083)$ & $(0.019)$ \\
& & & & & & & \\
0.55 & 0.50 & 0.45 & 0.66 & 0.86 & 0.91 & 1.00 & 1.30 \\
$(0.31)$ & $(0.40)$ & $(0.27)$ & $(0.58)$ & $(0.17)$ & $(0.27)$ & $(0.21)$ & $(0.41)$ \\
0.82 & 0.79 & 1.08 & 1.06 & 1.11 & 1.15 & 1.19 & 1.43 \\
$(0.19)$ & $(0.32)$ & $(0.27)$ & $(0.44)$ & $(0.15)$ & $(0.26)$ & $(0.16)$ & $(0.32)$ \\
0.64 & 0.23 & 0.63 & 0.22 & 0.88 & 0.42 & 0.94 & 1.24 \\
$(0.30)$ & $(0.21)$ & $(0.30)$ & $(0.19)$ & $(0.37)$ & $(0.27)$ & $(0.37)$ & $(0.77)$ \\
0.90 & 0.93 & 0.93 & 0.85 & $0.83^{*}$ & 0.83 & 0.91 & 0.86 \\
$(0.12)$ & $(0.29)$ & $(0.14)$ & $(0.29)$ & $(0.065)$ & $(0.17)$ & $(0.078)$ & $(0.17)$ \\
0.93 & 0.51 & 0.97 & $0.47 *$ & 1.03 & 1.00 & 1.06 & 0.96 \\
$(0.15)$ & $(0.18)$ & $(0.18)$ & $(0.17)$ & $(0.094)$ & $(0.23)$ & $(0.11)$ & $(0.23)$ \\
& & & & & & & \\
1.08 & 1.74 & 1.07 & 1.53 & 0.83 & $0.61 *$ & 0.84 & $0.52^{* *}$ \\
$(0.19)$ & $(0.72)$ & $(0.22)$ & $(0.64)$ & $(0.091)$ & $(0.14)$ & $(0.098)$ & $(0.11)$ \\
1.12 & 1.16 & 1.10 & 0.78 & 0.82 & 0.83 & 0.90 & 0.80 \\
$(0.19)$ & $(0.46)$ & $(0.21)$ & $(0.29)$ & $(0.086)$ & $(0.19)$ & $(0.10)$ & $(0.18)$ \\
1.07 & 0.79 & 0.91 & 0.54 & 0.89 & 0.79 & 0.96 & $0.66^{*}$ \\
$(0.19)$ & $(0.30)$ & $(0.18)$ & $(0.19)$ & $(0.096)$ & $(0.19)$ & $(0.11)$ & $(0.13)$ \\
$1.01 *$ & 1.02 & 1.01 & 1.01 & 1.00 & 1.01 & 1.00 & 1.00 \\
$(0.0058)$ & $(0.010)$ & $(0.0065)$ & $(0.011)$ & $(0.0032)$ & $(0.0069)$ & $(0.0034)$ & $(0.0074)$ \\
3.82 & 0.12 & 0.93 & 0.10 & 0.71 & 0.27 & $0.13 * * *$ & 0.26 \\
$(2.63)$ & $(0.16)$ & $(0.70)$ & $(0.15)$ & $(0.25)$ & $(0.20)$ & $(0.054)$ & $(0.20)$ \\
& & & & & & \\
4,148 & & 4,144 & & 22,877 & & 22,850 & \\
.06 & 0.12 & 0.21 & .22 & .06 & 0.09 & .40 & 0.45 \\
\hline
\end{tabular}


Table 2b: Logistic Regression of Disclosure on Dyad, Discussion and Respondent Characteristics, Odds-Ratio

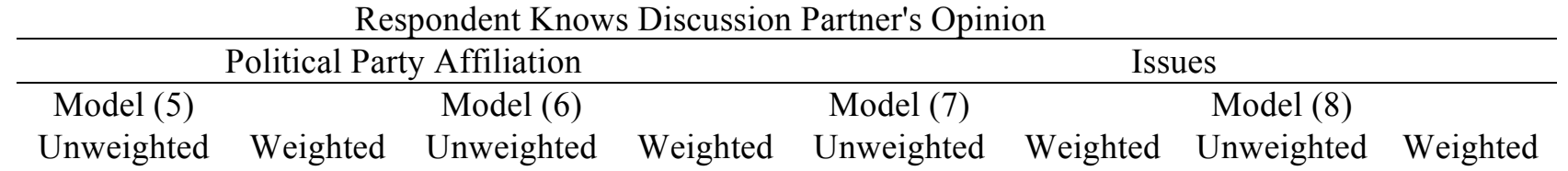

\begin{tabular}{|c|c|c|c|c|c|c|c|c|}
\hline Agreement & -- & -- & $\begin{array}{c}2.79 * * * \\
(0.33)\end{array}$ & $\begin{array}{l}2.01 * \\
(0.55)\end{array}$ & -- & -- & $\begin{array}{c}3.46 * * * \\
(0.22)\end{array}$ & $\begin{array}{c}3.01 * * * \\
(0.48)\end{array}$ \\
\hline \multicolumn{2}{|c|}{ Knowledge of Discussion Partner's Attitude } & -- & -- & -- & -- & -- & -- & -- \\
\hline \multicolumn{9}{|l|}{ Issue (ref is Welfare) } \\
\hline Abortion & -- & -- & -- & -- & $\begin{array}{c}1.15 \\
(0.092)\end{array}$ & $\begin{array}{c}0.93 \\
(0.20)\end{array}$ & $\begin{array}{c}0.93 \\
(0.076)\end{array}$ & $\begin{array}{c}0.75 \\
(0.16)\end{array}$ \\
\hline Gay Marriage & -- & -- & -- & -- & $\begin{array}{c}1.34 * * * \\
(0.11)\end{array}$ & $\begin{array}{c}1.26 \\
(0.26)\end{array}$ & $\begin{array}{c}1.07 \\
(0.087)\end{array}$ & $\begin{array}{c}0.98 \\
(0.22)\end{array}$ \\
\hline Affirmative Action & -- & -- & -- & -- & $\begin{array}{c}0.64 * * * \\
(0.048)\end{array}$ & $\begin{array}{c}0.67 \\
(0.15)\end{array}$ & $\begin{array}{c}0.50 * * * \\
(0.041)\end{array}$ & $\begin{array}{c}0.53 * * \\
(0.12)\end{array}$ \\
\hline Healthcare Reform & -- & -- & -- & -- & $\begin{array}{c}1.42 * * * \\
(0.12)\end{array}$ & $\begin{array}{c}1.13 \\
(0.25)\end{array}$ & $\begin{array}{c}1.30 * * \\
(0.11)\end{array}$ & $\begin{array}{c}0.96 \\
(0.22)\end{array}$ \\
\hline \multicolumn{9}{|l|}{ Relationship } \\
\hline Friends & $\begin{array}{c}0.95 \\
(0.13)\end{array}$ & $\begin{array}{c}0.93 \\
(0.28)\end{array}$ & $\begin{array}{c}1.02 \\
(0.15)\end{array}$ & $\begin{array}{c}1.01 \\
(0.32)\end{array}$ & $\begin{array}{c}1.07 \\
(0.092)\end{array}$ & $\begin{array}{c}0.85 \\
(0.17)\end{array}$ & $\begin{array}{c}1.05 \\
(0.091)\end{array}$ & $\begin{array}{c}0.88 \\
(0.17)\end{array}$ \\
\hline Coworkers & $\begin{array}{c}0.38 * * * \\
(0.070)\end{array}$ & $\begin{array}{c}0.50 \\
(0.24)\end{array}$ & $\begin{array}{c}0.43 * * * \\
(0.081)\end{array}$ & $\begin{array}{c}0.54 \\
(0.25)\end{array}$ & $\begin{array}{c}0.88 \\
(0.11)\end{array}$ & $\begin{array}{c}1.20 \\
(0.41)\end{array}$ & $\begin{array}{c}0.93 \\
(0.11)\end{array}$ & $\begin{array}{c}1.25 \\
(0.42)\end{array}$ \\
\hline Other & $\begin{array}{c}0.47 * * * \\
(0.084)\end{array}$ & $\begin{array}{c}0.47^{*} \\
(0.18)\end{array}$ & $\begin{array}{c}0.52 * * * \\
(0.098)\end{array}$ & $\begin{array}{c}0.53 \\
(0.20)\end{array}$ & $\begin{array}{c}0.58 * * * \\
(0.063)\end{array}$ & $\begin{array}{c}0.32 * * * \\
(0.082)\end{array}$ & $\begin{array}{c}0.64 * * * \\
(0.071)\end{array}$ & $\begin{array}{c}0.37 * * * \\
(0.092)\end{array}$ \\
\hline \multicolumn{9}{|c|}{ Interest in Politics (ref is not much interested) } \\
\hline Somewhat interested & $\begin{array}{c}1.12 \\
(0.30)\end{array}$ & $\begin{array}{c}0.43 \\
(0.31)\end{array}$ & $\begin{array}{c}1.07 \\
(0.29)\end{array}$ & $\begin{array}{c}0.43 \\
(0.30)\end{array}$ & $\begin{array}{c}1.21 \\
(0.20)\end{array}$ & $\begin{array}{c}1.24 \\
(0.40)\end{array}$ & $\begin{array}{c}1.34 \\
(0.22)\end{array}$ & $\begin{array}{c}1.20 \\
(0.35)\end{array}$ \\
\hline Very interested & $\begin{array}{c}1.64 \\
(0.46)\end{array}$ & $\begin{array}{c}0.59 \\
(0.45)\end{array}$ & $\begin{array}{c}1.55 \\
(0.43)\end{array}$ & $\begin{array}{c}0.61 \\
(0.44)\end{array}$ & $\begin{array}{l}1.58 * * \\
(0.27)\end{array}$ & $\begin{array}{l}2.23 * \\
(0.74)\end{array}$ & $\begin{array}{l}1.70 * * \\
(0.29)\end{array}$ & $\begin{array}{l}2.07 * \\
(0.61)\end{array}$ \\
\hline \multicolumn{9}{|l|}{ Ideology (ref is extremely liberal) } \\
\hline Liberal & $\begin{array}{c}0.74 \\
(0.20)\end{array}$ & $\begin{array}{c}1.52 \\
(1.12)\end{array}$ & $\begin{array}{c}0.78 \\
(0.21)\end{array}$ & $\begin{array}{c}1.61 \\
(1.15)\end{array}$ & $\begin{array}{l}0.74^{*} \\
(0.11)\end{array}$ & $\begin{array}{c}0.72 \\
(0.31)\end{array}$ & $\begin{array}{c}0.82 \\
(0.12)\end{array}$ & $\begin{array}{c}0.67 \\
(0.32)\end{array}$ \\
\hline Slightly liberal & 0.58 & 0.71 & 0.71 & 0.88 & $0.62 * *$ & 0.45 & $0.71 *$ & 0.42 \\
\hline
\end{tabular}




\begin{tabular}{|c|c|c|c|c|c|c|c|c|}
\hline \multirow{3}{*}{ Moderate } & $(0.16)$ & $(0.57)$ & $(0.20)$ & $(0.70)$ & $(0.096)$ & $(0.19)$ & $(0.11)$ & $(0.20)$ \\
\hline & $0.36^{* *}$ & 0.50 & $0.46^{*}$ & 0.64 & $0.69^{*}$ & 0.61 & 0.81 & 0.66 \\
\hline & $(0.11)$ & $(0.41)$ & $(0.15)$ & $(0.51)$ & $(0.13)$ & $(0.28)$ & $(0.15)$ & $(0.33)$ \\
\hline \multirow{2}{*}{ Slightly conservative } & $0.41 * *$ & 0.58 & $0.53^{*}$ & 0.75 & $0.58^{* *}$ & 0.76 & $0.66^{*}$ & 0.78 \\
\hline & $(0.12)$ & $(0.48)$ & $(0.16)$ & $(0.63)$ & $(0.099)$ & $(0.35)$ & $(0.11)$ & $(0.39)$ \\
\hline \multirow[t]{2}{*}{ Conservative } & 0.65 & 1.47 & 0.64 & 1.52 & 0.74 & 0.67 & 0.79 & 0.63 \\
\hline & $(0.20)$ & $(1.10)$ & $(0.20)$ & $(1.11)$ & $(0.13)$ & $(0.31)$ & $(0.14)$ & $(0.33)$ \\
\hline \multirow[t]{2}{*}{ Extremely conservative } & 1.25 & 2.59 & 1.18 & 2.57 & 0.83 & 0.55 & 0.80 & 0.53 \\
\hline & $(0.67)$ & $(2.61)$ & $(0.63)$ & $(2.53)$ & $(0.21)$ & $(0.26)$ & $(0.20)$ & $(0.29)$ \\
\hline \multirow[t]{2}{*}{ Gender } & 1.04 & $2.08 * *$ & 0.99 & $2.00^{*}$ & 1.07 & 1.00 & 1.09 & 1.02 \\
\hline & $(0.15)$ & $(0.59)$ & $(0.14)$ & $(0.55)$ & $(0.092)$ & $(0.18)$ & $(0.093)$ & $(0.20)$ \\
\hline \multicolumn{9}{|c|}{ Employment (ref is working as a paid employee) } \\
\hline \multirow[t]{2}{*}{ Self-employed } & 0.81 & $0.49^{*}$ & 0.83 & 0.52 & 0.95 & 0.90 & 0.98 & 0.88 \\
\hline & $(0.15)$ & $(0.18)$ & $(0.15)$ & $(0.19)$ & $(0.11)$ & $(0.22)$ & $(0.12)$ & $(0.23)$ \\
\hline \multirow[t]{2}{*}{ Not working, looking } & 1.02 & 0.80 & 1.00 & 0.81 & 0.92 & 0.89 & 0.91 & 0.85 \\
\hline & $(0.18)$ & $(0.31)$ & $(0.18)$ & $(0.31)$ & $(0.099)$ & $(0.19)$ & $(0.098)$ & $(0.19)$ \\
\hline \multirow[t]{2}{*}{ Retired } & 0.67 & 0.87 & 0.61 & 0.87 & 0.77 & 0.66 & 0.74 & 0.66 \\
\hline & $(0.24)$ & $(0.38)$ & $(0.23)$ & $(0.40)$ & $(0.16)$ & $(0.21)$ & $(0.16)$ & $(0.20)$ \\
\hline \multirow[t]{2}{*}{ Disabled } & 0.98 & 0.34 & 1.17 & 0.38 & 1.00 & 1.13 & 0.98 & 0.98 \\
\hline & $(0.34)$ & $(0.27)$ & $(0.42)$ & $(0.32)$ & $(0.24)$ & $(0.51)$ & $(0.25)$ & $(0.44)$ \\
\hline \multirow[t]{2}{*}{ Evangelical } & 0.83 & 0.68 & 0.80 & 0.67 & 0.95 & 0.77 & 0.96 & 0.80 \\
\hline & $(0.16)$ & $(0.25)$ & $(0.16)$ & $(0.25)$ & $(0.11)$ & $(0.16)$ & $(0.12)$ & $(0.18)$ \\
\hline \multirow[t]{2}{*}{ Religious Service Attendance } & 0.93 & 0.95 & 0.94 & 0.97 & 1.00 & 1.01 & 1.01 & 1.02 \\
\hline & $(0.047)$ & $(0.098)$ & $(0.049)$ & $(0.100)$ & $(0.032)$ & $(0.066)$ & $(0.033)$ & $(0.072)$ \\
\hline \multirow[t]{2}{*}{ Education } & 0.97 & 0.91 & 0.99 & 0.93 & 1.04 & 0.98 & 1.04 & 0.96 \\
\hline & $(0.051)$ & $(0.088)$ & $(0.053)$ & $(0.092)$ & $(0.033)$ & $(0.053)$ & $(0.033)$ & $(0.054)$ \\
\hline \multirow[t]{2}{*}{ Hispanic } & 1.62 & 1.24 & 1.44 & 1.18 & 0.84 & $0.61 *$ & 0.85 & 0.65 \\
\hline & $(0.44)$ & $(0.73)$ & $(0.39)$ & $(0.66)$ & $(0.12)$ & $(0.13)$ & $(0.12)$ & $(0.15)$ \\
\hline \multicolumn{9}{|l|}{ Race (ref is white) } \\
\hline \multirow[t]{2}{*}{ Black } & 0.87 & $2.70^{*}$ & 0.70 & 2.37 & 0.78 & 1.38 & 0.71 & 1.19 \\
\hline & $(0.24)$ & $(1.25)$ & $(0.20)$ & $(1.11)$ & $(0.13)$ & $(0.39)$ & $(0.13)$ & $(0.35)$ \\
\hline \multirow[t]{2}{*}{ Asian } & $0.56^{*}$ & 0.64 & $0.48 * *$ & 0.54 & 0.88 & $0.35 * *$ & 0.88 & $0.43 * *$ \\
\hline & $(0.13)$ & $(0.27)$ & $(0.11)$ & $(0.21)$ & $(0.14)$ & $(0.11)$ & $(0.14)$ & $(0.13)$ \\
\hline \multirow[t]{2}{*}{ Other } & 0.75 & 4.34 & 0.78 & 4.46 & 1.00 & 1.90 & 1.03 & 1.86 \\
\hline & $(0.25)$ & $(3.91)$ & $(0.26)$ & $(4.15)$ & $(0.17)$ & $(0.78)$ & $(0.18)$ & $(0.83)$ \\
\hline Income & 1.01 & $1.08^{*}$ & 1.01 & $1.08^{*}$ & 0.98 & 0.99 & 0.98 & 0.99 \\
\hline
\end{tabular}




\begin{tabular}{|c|c|c|c|c|c|c|c|c|}
\hline & $(0.018)$ & $(0.039)$ & $(0.018)$ & $(0.039)$ & $(0.010)$ & $(0.021)$ & $(0.010)$ & $(0.022)$ \\
\hline \multicolumn{9}{|c|}{ Marital Status (ref is married) } \\
\hline \multirow[t]{2}{*}{ Widowed } & 0.44 & 0.34 & 0.57 & 0.42 & 0.98 & 1.20 & 0.89 & 1.00 \\
\hline & $(0.30)$ & $(0.24)$ & $(0.37)$ & $(0.31)$ & $(0.27)$ & $(0.62)$ & $(0.24)$ & $(0.51)$ \\
\hline \multirow[t]{2}{*}{ Divorced } & 0.99 & 1.32 & 0.98 & 1.31 & 1.16 & 1.28 & 1.16 & 1.39 \\
\hline & $(0.28)$ & $(0.64)$ & $(0.28)$ & $(0.64)$ & $(0.21)$ & $(0.33)$ & $(0.21)$ & $(0.37)$ \\
\hline \multirow[t]{2}{*}{ Separated } & 0.79 & 0.25 & 0.58 & 0.19 & 1.03 & $4.97 *$ & 0.96 & $5.31^{*}$ \\
\hline & $(0.46)$ & $(0.24)$ & $(0.35)$ & $(0.19)$ & $(0.54)$ & $(3.50)$ & $(0.54)$ & $(3.73)$ \\
\hline \multirow[t]{2}{*}{ Never Married } & 0.86 & 0.94 & 0.87 & 0.96 & 0.86 & 0.73 & 0.91 & 0.88 \\
\hline & $(0.14)$ & $(0.35)$ & $(0.15)$ & $(0.35)$ & $(0.095)$ & $(0.16)$ & $(0.10)$ & $(0.21)$ \\
\hline \multirow[t]{2}{*}{ Cohabitating } & 0.92 & 0.53 & 0.94 & 0.55 & 1.09 & 0.72 & 1.13 & 0.83 \\
\hline & $(0.20)$ & $(0.23)$ & $(0.20)$ & $(0.25)$ & $(0.15)$ & $(0.20)$ & $(0.15)$ & $(0.25)$ \\
\hline \multicolumn{9}{|l|}{ Urban Status (ref is rural) } \\
\hline \multirow[t]{2}{*}{ Town } & 1.06 & 1.06 & 1.11 & 1.16 & 0.89 & $0.61 *$ & 0.90 & 0.63 \\
\hline & $(0.25)$ & $(0.52)$ & $(0.26)$ & $(0.57)$ & $(0.13)$ & $(0.14)$ & $(0.13)$ & $(0.16)$ \\
\hline \multirow[t]{2}{*}{ Small City } & 1.11 & 0.58 & 1.10 & 0.57 & 0.94 & 0.74 & 0.96 & 0.72 \\
\hline & $(0.24)$ & $(0.24)$ & $(0.24)$ & $(0.24)$ & $(0.14)$ & $(0.15)$ & $(0.14)$ & $(0.16)$ \\
\hline \multirow[t]{2}{*}{ Large City } & 0.91 & $0.33 * *$ & 0.91 & $0.35 * *$ & 1.07 & 0.66 & 1.09 & 0.68 \\
\hline & $(0.21)$ & $(0.13)$ & $(0.20)$ & $(0.14)$ & $(0.16)$ & $(0.15)$ & $(0.16)$ & $(0.16)$ \\
\hline \multirow[t]{2}{*}{ Age } & 1.01 & 1.01 & 1.01 & 1.01 & 1.00 & 1.00 & 1.00 & 1.01 \\
\hline & $(0.0073)$ & $(0.013)$ & $(0.0076)$ & $(0.012)$ & $(0.0044)$ & $(0.0075)$ & $(0.0044)$ & $(0.0080)$ \\
\hline \multirow[t]{2}{*}{ Constant } & $16.2 * *$ & 11.8 & $7.52 *$ & 5.44 & $3.07 *$ & $10.9^{*}$ & 1.20 & 6.05 \\
\hline & $(14.0)$ & (20.9) & $(6.54)$ & $(9.97)$ & (1.59) & $(10.5)$ & $(0.62)$ & $(5.98)$ \\
\hline Observations & 3,499 & & 3499 & & 12,312 & & 12,312 & \\
\hline Adjusted R-squared & .05 & .16 & .09 & .09 & .03 & .06 & .08 & .09 \\
\hline
\end{tabular}

